\title{
WHY PARENTS REFUSE NEWBORN HEARING SCREENING AND DEFAULT ON FOLLOW-UP RESCREENING - A SOUTH AFRICAN PERSPECTIVE
}

By

Lucia Jane Scheepers

A dissertation submitted in fulfilment of the requirements for the degree M. Communication Pathology in the Department of Speech-Language Pathology and Audiology UNIVERSITY OF PRETORIA FACULTY OF HUMANITIES

SUPERVISOR: Prof. De Wet Swanepoel CO-SUPERVISOR: Mrs Talita Le Roux

November 2014 


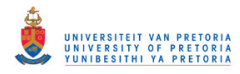

(C) University of Pretoria 


\section{TABLE OF CONTENTS}

1. INTRODUCTION

1.1. Background 1

1.2. Impact of hearing loss 2

1.3. EHDI in South Africa 3

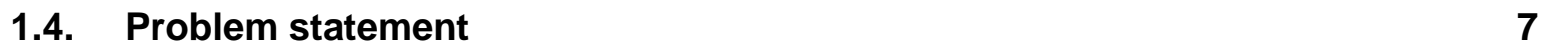

2. METHODOLOGY 8

$\begin{array}{llr}\text { 2.1. } & \text { Research aims } & 8\end{array}$

2.2. Research design 9

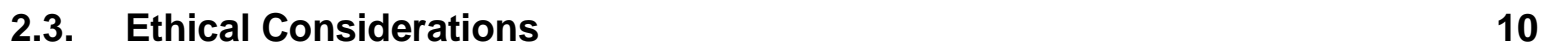

2.3.1. Respect for persons 10

2.3.2. Beneficence and non-malfeasance 11

2.3.3. Professional ethics 12

2.4. Criteria and procedures for selection of participants 12

2.4.1. NHS retrospective record review (Study I) 12

$\begin{array}{ll}\text { i. } & \text { Research population } \\ \end{array}$

ii. Research sample 13

iii. Data collection material 13

iv. Data collection apparatus 14

v. Data collection procedure 14

2.4.2. Surveys of screen refusal (Study II) and follow-up default (Study III) 16

$\begin{array}{ll}\text { i. } & \text { Research population } \\ \end{array}$

$\begin{array}{lr}\text { ii. } & \text { Research sample } \\ \end{array}$

iii. Data collection material and apparatus 16

iv. Telephonic survey: reason for follow-up default (Appendix E) 18

v. Data collection procedure 19

2.5. Data processing and analysis procedure 20

2.6. Validity and reliability 21

3. RESEARCH ARTICLE 23

3.1. Abstract 23

3.2. Introduction 24

$\begin{array}{ll}\text { 3.3. } & \text { Method } 26\end{array}$ 
3.3.1. Research context 26

3.3.2. NHS retrospective record review - Study I 26

3.3.3. Surveys of screen refusal (Study II) and follow-up default (Study III) 28

$\begin{array}{llr}\text { 3.4. Results } & 29\end{array}$

3.4.1. NHS retrospective record review - Study I 29

3.4.2. Screen refusal survey - Study II 30

3.4.3. Follow-up default survey - Study III 32

$\begin{array}{lll}\text { 3.5. Discussion } & 34\end{array}$

3.5.1. NHS retrospective record review - Study I 34

3.5.2. NHS prospective surveys - Study II and Study III 36

i. Reasons for screen refusal 36

ii. Reasons for follow-up default $\quad 37$

$\begin{array}{ll}\text { 3.6. Conclusion } & 39\end{array}$

4. DISCUSSION AND CONCLUSION $\quad 40$

4.1. Discussion of results $\quad 40$

4.1.1. NHS retrospective record review - Study I $\quad 40$

i. Coverage and screen refusal $\quad 40$

ii. Follow-up rate 43

4.1.2. NHS prospective surveys - Study II and Study III $\quad 44$

i. Reasons for screen refusal and follow-up default 44

4.2. Clinical implications and recommendations 47

4.3. Critical evaluation 49

4.4. Suggestions for future research 50

4.5. Conclusion 50

5. REFERENCES 52

6. APPENDICES 60

Appendix A: Letter of consent: Private practice owner i

Appendix B: Ethical clearance letter v v

Appendix C: Retrospective record review (Study I) data collection form vii

Appendix D: Telephonic Survey: Reasons for screen refusal (Study II) xi

Appendix E: Telephonic Survey: Reasons for follow-up default (Study III) XV 


\section{FIGURES}

Figure 1. Newborn hearing screening referral rate and follow-up return rate $\quad 29$ Figure 2. Average age of infants who passed or referred newborn hearing $\begin{array}{ll}\text { screening } & 30\end{array}$

Figure 3. NHS importance as perceived by caregivers who refused hearing screening $(n=25) \quad 32$

Figure 4. Person responsible for NHS as perceived by caregivers who refused NHS $(n=25)$ and who defaulted on follow-up retest $(n=25)$

\section{TABLES}

Table 1. Caregivers' reasons for declining the NHS screen $(n=25)$

Table 2. Caregivers' reasons for defaulting on follow-up appointment $(n=25)$ 33 


\section{INTRODUCTION}

\subsection{Background}

Permanent hearing loss occurs more frequently than any other condition for which children are routinely screened or for which early detection has been proven beneficial (White \& Blaiser, 2011). Approximately 5.3\% (360 million) of the world's population suffers from disabling hearing loss ( $>40 \mathrm{~dB} \mathrm{HL}$ ); $9 \%$ (32 million) of these are children, with $1.9 \%(6.8$ million) residing in sub-Saharan Africa where, along with south Asia, the prevalence of disabling hearing loss in children is highest (World Health Organisation, 2012). The incidence of permanent congenital and early-onset hearing loss in developing countries, where environmental risks are more prevalent and early identification programmes are extremely rare, has been estimated to be not less than six per 1000 births annually (Olusanya \& Newton, 2007). This finding equates to approximately 718000 infants with permanent bilateral hearing impairment in the developing world annually (Olusanya \& Newton, 2007). Alarmingly, $25 \%$ of all infants born with permanent bilateral hearing loss (an estimated 180000 infants) are born each year in sub-Saharan Africa (Olusanya, et al., 2007).

In South Africa, the prevalence of childhood hearing loss has been estimated at 5.5 per 1000 births (Swanepoel, Störbeck \& Friedland, 2009) whereas in more developed countries, such as the US and the UK, the incidence of acquired sensori-neural hearing loss (SNHL) has fallen over the past three to four decades (Smith, Bale \& White, 2005). In these countries, a prevalence of 1.33 to 4 per 1000 births is reported (Morton \& Nance, 2006; Smith, Bale \& White, 2005). Such changes in the incidence of acquired SNHL have not been observed in children living in less developed countries where the incidence of both genetic and acquired SNHL is high, especially in children living in poverty (Smith, Bale \& White, 2005).

The goal of newborn hearing screening (NHS) and early intervention is to minimise the negative effects of hearing loss on speech and language development (Olusanya, 2012) and to improve long-term developmental outcomes through timely identification and effective intervention (Ching, Day, Seeto, Dillion, Marnane \& Street, 2013; Moeller, White \& Shisler, 2006; Yoshinaga-Itano, 2003;). As hearing loss is invisible in nature, it is impossible to identify it through routine clinical examinations. Hearing screening based on the use of hearing loss risk factors alone fails to detect as many as $40 \%$ to $50 \%$ of infants with a hearing loss in the US (Olusanya, Luxon \& Wirz, 2004a; Yoshinaga-Itano \& Gravel, 2001). The implementation of NHS programmes using objective physiological measures (Health 
Professions Council of South Africa, 2007; Joint Commission on Infant Hearing, 2007) ensures the early detection of infants with hearing impairment. The introduction of physiological measures to assess the hearing of newborn infants has revolutionised service delivery and is the method of choice for the most effective NHS programs (Nelson, Bougatsos \& Nygren, 2008; Yoshinaga-Itano, Coulter \& Thomson, 2001; Yoshinaga-Itano \& Thomson, 2008). Test procedures including Otoacoustic Emissions (OAE) and Automated Auditory Brainstem Responses (AABR) are recommended by the Joint Committee on Infant Hearing $(\mathrm{JCIH}, 2007)$ and the Health Professions Council of South Africa (HPCSA) in the Position Statement on Early Hearing Detection and Intervention (EHDI) programmes (HPCSA, 2007). Both technologies are noninvasive measures of physiological activity and are easily and quickly measured in less than five minutes in sleeping newborns (Mehl \& Thomson, 1998).

Infants with congenital hearing loss identified through universal NHS (UNHS) have significantly earlier referral, diagnosis and intervention than those identified in other ways (Nelson, Bougatsos \& Nygren, 2008); furthermore, infants born in hospitals that offer NHS, present with superior speech and language outcomes (Pimperton \& Kennedy, 2012). As a result of these programmes in developed counties, where the majority ( $97.9 \%$ in the US) (Pallarito, 2012) of newborn infants are screened for hearing loss, the average age of detection of children with hearing loss has fallen from between 12 and 18 months to six months or younger (Smith, Bale \& White, 2005) with the average age of confirmation of hearing loss falling from between 24 and 30 months to between 2 and 3 months (Harrison, Roush \& Wallace, 2003).

No other type of hearing screening programme has demonstrated the same efficacy as UNHS in decreasing the age of hearing loss identification and intervention resulting in ageappropriate outcomes for the infant (Yoshinaga-Itano, 2004).

\subsection{Impact of hearing loss}

National and international bodies recommend that all newborns have their hearing screened before they are a month old, that those who fail screening undergo diagnostic testing by the age of three months and that intervention is initiated by the age of six months for infants who have a hearing loss (HPCSA, 2007; JCIH, 2007; Pallarito, 2012). A large body of research has established that infants identified with a mild to profound hearing loss and who are provided with immediate and appropriate intervention by six months of age demonstrate superior language, speech and social-emotional development when compared to their later 
identified peers (Meinzen-Derr, Wiley \& Choo, 2011; Morton \& Nance, 2006; Nelson, Bougatsos \& Nygren, 2008; Pimperton \& Kennedy, 2012; Yoshinaga-Itano \& Gravel, 2001).

Early language development paves the way for later educational and academic success (Ching, Day, Seeto, Dillion, Marnane \& Street, 2013) and significantly better language scores and developmental outcomes in children with a hearing loss have been associated with early enrolment in intervention programmes (Fulcher, Purcell \& Baker et al., 2012; Kemper, 2011). Most children who are identified with a hearing loss by the age of three months, and who receive amplification and intervention by six months, develop ageappropriate speech and language by the time they are three and maintain this progress for two years, regardless of the severity of the hearing loss (Fulcher, Purcell \& Baker et al., 2012; Meinzen-Derr, Wiley \& Choo, 2011).

A language delay of between two to four years has been found to occur in infants identified after six months of age. Late identification of hearing loss leads to delays not only in language, but also in speech, reading and writing, academic achievement and in personal and social development (Olusanya, 2012; Yoshinaga-Itano \& Gravel, 2001). Furthermore, the societal and economic burdens of late or undiagnosed hearing loss are high, especially in developing countries (Olusanya, 2012). EHDI offers an opportunity to prevent the dire developmental outcome trajectory for a child with a permanent hearing loss (Olusanya, 2012).

The success of NHS programmes in developed countries has enormous personal, societal and economic benefits and the spread of such programmes across the globe has been revolutionary in healthcare (Morton \& Nance, 2006). The benefits of EHDI programmes go beyond speech and language development in resource-poor countries (Olusanya, 2012). However, finding the resources for developing and standardising NHS programmes is a major challenge in developing countries (Morton \& Nance, 2006) where the lifetime burden of hearing loss is aggravated by a lack of provision within the existing health (Friderichs, Swanepoel \& Hall, 2012) and educational system and where there are adverse societal perceptions of child disability (Olusanya, 2012).

\subsection{EHDI in South Africa}

Routine NHS programmes are rare in resource-poor developing countries, such as South Africa, and which account for the vast majority of infants with permanent congenital hearing loss (Olusanya, 2012). The scarcity and unsystematic nature of NHS programmes in developing counties manifests itself in the fact that most infants born with a hearing loss will 
have little prospect of early detection and immediate intervention (Swanepoel \& Störbeck, 2008), leading to restricted developmental outcomes (Meyer \& Swanepoel, 2011).

In South Africa, which combines elements of both a developed and an underdeveloped country, unique and diverse challenges that affect screening coverage, referral and follow-up rates arise. These challenges may be exacerbated by the country's global economic standing and the screening programme delivery mechanism (hospital based or clinic based) (Tann, Wilson, Bradley \& Wanless, 2009). The heavy burden of infectious diseases, including HIV/AIDS, and a lack of contextual hearing loss prevalence data further hamper the development and implementation of hearing screening programmes in South Africa (Morton \& Nance, 2006; Swanepoel, Delport \& Swart, 2004; Swanepoel, Ebrahim \& Joseph et al., 2007), where it has been reported that fewer than $3 \%$ of birthing units offer UNHS (Meyer, Swanepoel, le Roux \& van der Linde, 2012).

The South African health care system consists of a state run and taxpayer-funded public health care sector and a private sector, which caters for those individuals covered by private medical insurance or those who pay for care themselves. It is estimated that $16 \%$ to $45 \%$ of the population access private health care while between $55 \%$ and $84 \%$ use public health care facilities (Biermann, 2006). Only $27 \%$ and $53 \%$ of hospitals in the public and private health care sectors respectively offer NHS services (Meyer, Swanepoel, le Roux \& van der Linde, 2012; Theunissen \& Swanepoel, 2008), and UNHS is offered by only $14 \%$ of hospitals in the private health care sector (Meyer, Swanepoel, le Roux \& van der Linde, 2012). In the private health care sector, EHDI services remain mostly unstructured, unsystematic and available only in certain hospitals (Swanepoel, Störbeck \& Friedland, 2009) and dependent on initiatives by individuals. Observations reveal that EHDI services are limited and restricted to urban areas (Swanepoel, Ebrahim \& Joseph et al., 2007).

The absence of legislation and a lack of awareness regarding EHDI in South Africa means that the initial detection of hearing loss often occurs only as the result of parental concern over delayed speech and language development in an infant, and at ages where critical developmental periods have already passed (HPCSA, 2007; Swanepoel, Störbeck \& Friedland, 2009). A recent study found a delay of 22 months between initial parental suspicion of childhood hearing loss and diagnosis (Swanepoel, Johl \& Pienaar, 2013). In South Africa, the average age of first diagnosis of hearing loss ranges from 23 to 42 months (Swanepoel, Johl \& Pienaar, 2013; Swanepoel, Störbeck \& Friedland 2009; Theunissen \& Swanepoel, 2008; Van der Spuy \& Pottas, 2008), an age at which the critical periods for language development have already passed (Meyer \& Swanepoel, 2011; Swanepoel, Johl \& 
Pienaar, 2013). These substantial delays in diagnosis of hearing loss are evidence of the dearth of EHDI programmes in South Africa.

One issue that threatens the effectiveness of the NHS effort is the failure to screen the hearing of all infants universally (Goedert, Moeller \& White, 2011). In developed countries such as the US, the majority of infants (97.9\%) are screened for hearing loss (Pallarito, 2012) and every state offers either mandatory or voluntary NHS (Nelson, Bradham \& Houston, 2011). However, despite the demonstrated advantages of NHS for optimal outcomes in infants with hearing loss (Moeller, 2000; Yoshinaga-Itano \& Apuzzo, 1998; Yoshinaga-Itano, Sedey \& Coulter et al., 1998), it is still not legislated or mandated in South Africa. As a result, caregivers may decline hearing screening of their infants. This problem is compounded specifically in the South African private health care sector where caregivers are charged for the hearing screening test. The omission of NHS from institution birthing packages and policy has been cited as the biggest challenge facing UNHS in the private health sector (Meyer \& Swanepoel, 2011).

The shortage of NHS services in the private health sector and their unsystematic nature have been attributed to several factors: the omission of NHS services from hospital birthing packages, health care institutional policy and the failure of medical insurers to reimburse individuals for the cost of NHS (Meyer \& Swanepoel, 2011; Meyer, Swanepoel, le Roux \& van der Linde, 2012). As a result, NHS becomes an out of pocket expense for caregivers. These obstacles are compounded by a lack of awareness of the importance of NHS among other health care professionals and the public (Meyer \& Swanepoel, 2011; Olusanya, Luxon $\&$ Wirz, 2004a). Screen refusal and coverage are also influenced by caregiver knowledge and attitudes towards NHS (Olusanya, Luxon \& Wirz, 2004a; Olusanya, Luxon \& Wirz, 2004b), both of which could be improved through support of NHS by medical professionals involved in the newborn's care (Moeller, White \& Shisler, 2006; Olusanya, Luxon \& Wirz, 2004a). The limited empowerment of caregivers and different cultural perceptions of disability have a detrimental effect on the level of caregiver involvement in intervention (Olusanya, 2009; Swanepoel, 2006; Van der Spuy \& Pottas, 2008). In the public health care sector, the situation is exacerbated by inadequate equipment and training and staff shortages (Olusanya, Luxon \& Wirz, 2004a; Theunissen \& Swanepoel, 2008).

The JCIH (2007) has listed a number of challenges that should be urgently addressed if the development of future EHDI services is to be ensured. One of these obstacles is the unsatisfactory follow-up rate for re-screening following initially failed NHS. Despite the comprehensive EHDI programme service implementation in the US (97.9\%) (Pallarito, 
2012), between almost 30\% (Gaffney, Green \& Gaffney, 2010) and half of all newborns who fail initial screening do not have appropriate follow-up to either confirm the presence of a hearing loss or to implement appropriate intervention $(\mathrm{JCIH}, 2007)$. Diagnostic testing of an infant who has failed NHS is essential in determining whether a hearing loss exists and is key to early intervention (Gaffney, Green \& Gaffney, 2010).

This trend towards poor follow-up rates also seems to be evident in South Africa, where loss to follow-up has been cited as a major weakness of existing NHS programmes (Meyer, Swanepoel, le Roux \& van der Linde, 2012). To date, NHS follow-up return rates in both the private and public health care sectors in South Africa have failed to meet the recommended minimum of more than $70 \%$ (HPCSA, 2007). Only a minority (28\%) of existing hospitalbased NHS programmes in the private health care sector meet national and international benchmarks for follow up (HPCSA, 2007; JCIH, 2007; Meyer, Swanepoel, le Roux \& van der Linde, 2012). In a study conducted at immunisation clinics (Swanepoel, Hugo \& Louw, 2006), it was found that fewer than half the infants (40\%) referred for follow-up hearing screening returned for their follow-up evaluations. This suggests the need for an investigation of caregivers' reasons for screen refusal and follow-up default in South Africa, as well as globally.

Some progress in initiating pilot early hearing detection and intervention programmes has been reported in developing countries; however, their benefits are still only reaching a very limited number of people (Olusanya et al., 2007). Although governmental and nongovernmental organisations in developing countries have begun to develop programmes to prevent childhood hearing loss or to offer rehabilitation, little or slow progress has been reported (Olusanya, Luxon \& Wirz, 2004a). In South Africa, there is a relatively well developed infrastructure and health care system compared to the rest of sub-Saharan Africa (Swanepoel, Störbeck \& Friedland, 2009). Despite this, apart from isolated programmes in South African private and public health care sectors, early identification of hearing loss is not being achieved (Swanepoel, Delport \& Swart, 2004; Swanepoel, Johl \& Pienaar, 2013; Van der Spuy \& Pottas, 2008).

Recommendations by the JCIH (2007) state that all EHDI services should have a sound information infrastructure and that data management and tracking systems should be integrated as part of the EHDI service. The HPCSA EHDI position statement (2007) also recognises the importance of recording and monitoring hearing screening and intervention data to determine the long term outcomes of children with hearing loss, EHDI programme cost effectiveness and to ensure continuous quality improvement in South Africa. Data 
management and analysis is important in determining the nature and impact of hearing loss in infants and in establishing the standard and scope of audiological services, in order to ensure an appropriate course of action in South Africa (Swanepoel, Delport \& Swart, 2004). Swanepoel, Ebrahim \& Joseph et al. (2007) have reported that research evidence of EHDI programmes in developing countries, especially in sub-Saharan Africa, are extremely limited. Initiating and reporting on pilot studies are important steps in providing contextual evidence of childhood hearing loss and assessing the efficacy of screening programmes in these countries.

\subsection{Problem statement}

The current study aims to complement and expand on the limited available research findings by describing the efficacy of the NHS programmes at two private health care hospitals in two different areas of the Western Cape.

Caregiver screen refusal and follow-up default are major barriers to the success of NHS programmes (Gaffney, Green \& Gaffney, 2010; Hoffman, Muñoz, Bradham \& Nelson, 2011; Tann et al., 2009) in South Africa. In order to increase the coverage rate and improve service delivery, the various reasons caregivers provide for screen refusal and follow-up default must be investigated. This study aims to investigate caregivers' reasons for screen refusal and follow-up default in hospital-based universal NHS programmes in the Western Cape, South Africa. As yet, no study in South Africa has investigated these reasons. 


\section{METHODOLOGY}

\subsection{Research aims}

\section{Main Aim}

The main research aim of this study was to describe caregivers' reasons for screen refusal (Study II) and follow-up default (Study III) over a 31 to 33-month period at two private health care hospitals (Hospital A and Hospital B) in two different areas of the Western Cape. A secondary research aim was to describe the efficacy of the NHS programmes at these two hospitals (Study I).

\section{Sub-aims}

The following sub-aims were formulated to facilitate the achievement of the main and secondary research aims:

1. To describe the efficacy of the screening characteristics of the programmes based on proposed national and international benchmarks (HPCSA, 2007; JCIH, 2007), to determine the degree to which these programmes meet the desired outcomes, according to:
a) Coverage
b) Initial referral rate
c) Percentage of unilateral and bilateral referrals
d) Average age of infants at NHS
e) Percentage of caregiver screen refusals
f) The effect of programme duration and infant age on initial referral rates

2. To describe the follow-up characteristics of the programmes according to:
a) Follow-up rate of infants referred for rescreen
b) Average age of infants at hearing screening follow-up

3. To describe caregivers' reasons for screen refusal

4. To describe caregivers' reasons for follow-up default

Results were compiled and described in the article entitled "Why parents refuse newborn hearing screening and default on follow-up rescreening - a South African perspective" (chapter 3) which was published electronically ahead of print in January 2014. 


\subsection{Research design}

\section{NHS retrospective record review (Study I)}

The study employed a non-experimental quantitative research approach as a large representative sample of numerical data was statistically analysed according to predetermined methods in order to explain the relationship between predetermined variables (Leedy \& Omrod, 2005). The primary component of this study used a descriptive retrospective research design. The study as a whole was contextually based.

Using the descriptive method allowed the researcher to gain a complete and accurate account of the characteristics of the NHS programmes at two private hospitals in two different areas of the Western Cape (Struwig \& Stead, 2001). The descriptive method meant that the researcher collected a large quantity of data and then extracted specific information in order to describe it (Hicks, 2004). Specific variables of interest (identified in the sub-aims of the study) were identified and only data related to those specific variables were collected (Leedy \& Omrod, 2005). Correlations were used to explore and describe the relationships between the variables.

As the primary component of the study focused on a record review of the NHS programmes at two private hospitals over a 31 to 33 -month period, a retrospective design was employed (Hicks, 2004). The record review entailed analysing hearing screening record forms which were completed for every infant enrolled in the NHS programmes. Demographic, maternal, neonatal and hearing screening outcome information was included on the hearing screening record form and was documented on a data collection form developed by the researcher (Appendix C).

\section{Surveys of screen refusal (Study II) and follow-up default (Study III)}

A sub-component using a prospective research design was included in the study. Twentyfive caregivers who declined hearing screening for their infants and 25 caregivers who failed to bring their infants for a scheduled follow-up hearing screening were identified and information was collected from them according to clearly defined criteria using a survey (Hicks, 2004). These 50 participants were randomly selected. Data from this sub-group shed light on the reasons for screen refusal and follow-up default in two private hospitals in the Western Cape (Leedy \& Omrod, 2005) serving two different areas and communities.

The participants were interviewed telephonically, using partially open-ended questions which provided a set of dichotomous and nominal closed-ended and open-ended response options 
(Appendix D and Appendix E). The use of standardised, closed-ended questions allowed participants' answers to be easily compared and quantified (Mrug, 2010).

\subsection{Ethical Considerations}

Ethical clearance, in compliance with the regulations of the Ethical Committee of the Faculty of Humanities, University of Pretoria, South Africa was obtained prior to commencing the study.

\subsubsection{Respect for persons}

\section{Informed consent}

Informed consent was obtained from the owner of the private practices situated in each hospital to access the retrospective hearing screening record forms in order to use this information on a private and confidential basis (Appendix A). Information regarding the nature of the study and the actions to be performed during the study was provided to the owner of the private practices in the form of a written letter (Appendix A). All identifying information was kept strictly confidential and no names were used at any time in the data collection process as each participant was allocated a code, thereby protecting caregiver and infant interests.

Caregivers' consent was obtained before proceeding with hearing screening. Caregivers were informed of the nature of OAE hearing screening, the benefits of hearing screening in terms of early identification of hearing loss and subsequent intervention. Caregivers were thoroughly informed of the possible temporary physical discomfort to the infant and emotional risks that may have been associated with participation in the study.

The participants in the telephonic survey were informed verbally of the nature of the study and the actions required from participants. This information was also included, together with the questions asked during the telephonic survey, on the data collection form developed by the researcher (Appendix $D$ and Appendix E). The telephonic survey data collection form included a response box indicating whether the participant had provided informed consent. Participants were informed of the voluntary nature of the study in order to make an informed and reasonable decision as to whether to participate (Leedy \& Omrod, 2005).

Participants were made aware of the principles protecting their interests, to which the researcher strictly adhered. These included participant confidentiality and privacy, disclosure 
of any participation risks and benefits, free withdrawal from the study at any time, free access to the findings of the study and ethical clearance from the relevant ethical committees (Leedy \& Omrod, 2005).

\section{Privacy and confidentiality}

The researcher ensured that the nature and quality of the participants' performance, views and beliefs were kept strictly confidential at all times by ensuring that only the researcher was aware of the identity of the participants (De Vos, Strydom, Fouché \& Delport, 2005). No names of participants or identifiers were used anywhere in the research report or the documented data (Leedy \& Omrod, 2005) as the researcher used a data-coding procedure that allocated a number to each participant when analysing the data. This safeguarded confidentiality and preserved anonymity (Maxwell \& Satake, 1997). In this manner, anonymity was assured as no one, including the researcher, was able to identify the participants upon completion of the research report (De Vos, Strydom, Fouché \& Delport, 2005).

\subsubsection{Beneficence and non-malfeasance}

Protection of participants from undue harm, whether it is of a physical or psychological nature, is obliged from any researcher (Leedy \& Omrod, 2005). However, according to Maxwell and Satake (1997), any study entails some degree of risk, thus the potential for risk must be weighed against the possible benefits for the participants and the scientific community.

The owner of the private practices and the participants in the telephonic survey were thoroughly informed of the possible physical discomfort and emotional risks that may have been associated with participation in the study. A letter of informed consent was sent to the owner of the private practices (Appendix A) and participants were informed verbally at the start of the telephonic survey (Appendix D and Appendix E). Participants were informed of their right to withdraw from the study at any time without any adverse consequences.

As the main component of the study encompassed a retrospective record review of the NHS programme, informed consent was obtained from the owner of the private practices to make use of this information (Appendix A) on a private and confidential basis. In this way the interests of the caregiver and infant were protected and safeguarded at all times. As previously indicated, all information identifying caregivers and infants was kept strictly confidential and no names were used at any time in the data collection process as each participant was allocated a code. 


\subsubsection{Professional ethics}

Mouton (2001) observes that researchers have an obligation to the scientific community to make the search for truth and knowledge moral and that those researchers have the right to search for this truth, but not at the risk of others in the society. This moral commitment was upheld in this case as the researcher is adequately qualified and competent and was supervised throughout the study.

The researcher ensured that no data was falsified or fabricated and that all findings were fully reported and not misinterpreted in any manner. The limitations of the findings and the methodology are indicated in this document. As the University of Pretoria will retain the raw data collected for 15 years, data will be made available to other researchers upon consideration of the advantages to the research community and community at large and with the permission of all parties involved (De Vos, Strydom, Fouché \& Delport, 2005). Findings have been reported in the public sphere in an open and timely fashion, allowing for public and peer review. The contributors to the study have been duly noted as co-authors. The researcher has avoided plagiarism by employing thorough referencing techniques (De Vos, Strydom, Fouché \& Delport, 2005).

\subsection{Criteria and procedures for selection of participants}

Population parameters and sampling procedures are of vital importance to the success of a study (Leedy \& Omrod, 2005). This section will discuss the research population and research sample that were included in the study.

\subsubsection{NHS retrospective record review (Study I)}

\section{Research population}

In keeping with the main aim of the study, the population included all infants who had participated in the NHS programmes at two private hospitals in the Western Cape over a 31 to 33-month period. Thus all infants enrolled in the programmes from May 2007 until December 2009 (Hospital A), and from July 2007 until December 2009 (Hospital B) were included in the study, both those for whom NHS was conducted and those whose caregivers had declined participation in the NHS programme. Thus, a universal approach to the research population was adopted as all infants born within this time frame were part of the study. Participants were selected through the use of non-probability convenience sampling method. 


\section{Research sample}

The research sample for the main component of the study, the retrospective record review, included all infants born between May 2007 until December 2009 (Hospital A), and from July 2007 until December 2009 (Hospital B) who were enrolled in the established NHS programmes at two private hospitals in the Western Cape.

\section{Data collection material}

As the main component of the study was retrospective in nature, the existing data collected on hearing screening record forms by the private hospitals over a 31 to 33-month period was used. Permission to access this data was obtained from the owner of the private practices (Appendix A). A hearing screening record form had been completed previously by an audiologist for every infant enrolled in the NHS programme. This form was used to record demographic information, hearing screening results as well as possible risk factors for hearing loss. This information was obtained from hospital records and/or by interviewing the caregivers and conducting the hearing screening test.

The researcher developed a data collection form (Appendix C) which was used to transfer and record the data entered on the hearing screening record forms. This data collection form consisted of three sections: demographic information, initial test and follow-up test, which will be discussed below.

\section{- Section A: Demographic information}

Each participant was allocated a participant code. Infant and maternal demographic information was collected from the hearing screening record form and recorded on the data collection form, including infant birth date, sex, birth weight, APGAR scores (at 1 and 5 minutes), birth type, pregnancy duration, maternal age and possible risk factors, including whether the infant was admitted to the Neonatal intensive Care Unit (NICU). The name of the medical aid was listed in cases where the infant and caregiver had made use of one.

\section{- Section B: Initial test}

Should the caregiver have declined hearing screening for their infant this was collected from the hearing screening record form and recorded on the data collection form. The date of the initial test, the age of the infant and the result of the initial test was collected and recorded. The researcher noted where the test had taken place and whether a follow-up retest at six weeks of age had been recommended. 


\section{- Section C: Follow-up test}

The date of the follow-up test, the age of the infant and the result of the test was recorded on the data collection form. If the caregiver had defaulted on the recommended follow-up, this was indicated on the hearing screening record form and recorded on the data collection form.

The researcher developed a key, included on the data collection form, to ensure that data collection was speedy and efficient. Each possible variable was allocated a number. This facilitated the analysis of the data.

\section{Data collection apparatus}

Audiologists employed by the private practice situated at each hospital conducted the screening daily, except on Sundays. Automated Distortion Product OAE were used for screening (Biologic AuDx). Screening parameters included the evaluation of the frequencies from 2, 3, 4 and $5 \mathrm{kHz}$ using a 65/55dB SPL stimulus level (L1/L2). Three of the four frequencies were required for the infant to pass, with a minimum distortion product amplitude of between -5 and $-8 \mathrm{~dB}$ SPL, a maximum noise floor amplitude of $14 \mathrm{~dB}$ SPL and a minimum signal-to-noise ratio of $6 \mathrm{~dB}$ SPL for an overall pass result. Distortion Product OAE have shown to have good test-retest repeatability (Wagner, Heppelmann, Vonthein \& Zenner, 2008). The devices used were calibrated by the South African distributors annually.

\section{Data collection procedure}

As the main component of the study was retrospective in nature, the data used came from existing hearing screening record forms collected over a period of between 31 and 33 months at two private hospitals. This previously collected hearing screening data encompassed two sets of data for each infant enrolled in the infant hearing screening, namely a completed medical case history and high-risk register, and bilateral OAE screening result. The data collection procedure that was adhered to is discussed below.

Caregivers were approached one to three days after the birth of the infant, prior to discharge. NHS was explained to the caregiver and subsequently offered as a fee-based service. If caregivers were discharged before being offered the hearing screening they were contacted telephonically and informed of the NHS service. Only infants from the well-baby nurseries were included in this study. Written consent was required from caregivers before hearing screening could proceed. Record was kept of every infant enrolled in the NHS programme, whether the respective caregiver had declined or agreed to the hearing 
screening. This hard copy record form included demographic information and hearing screening results if hearing screening had been conducted.

At both hospitals, infants were screened in the nursery, at the caregiver's bedside or in the audiology private practice situated inside the hospital building, and in a room with acceptably low noise levels. The NHS programme protocol was based on the guidelines set down by the Health Professions Council of South Africa (HPCSA) Year 2007 position statement on EHDI for South Africa (HPCSA, 2007). If the hearing screening yielded a unilateral or bilateral refer, a rescreen within six weeks of the first screen was recommended. Caregivers were required to arrange a convenient appointment date and to bring the infant to the private audiology practice for this rescreen. An information leaflet was given to all caregivers, providing general information on NHS and the contact details of the audiology practice. A sticker was placed on the infant's clinic card and hospital file indicating the practice's contact details and whether NHS had been declined, passed or a rescreen recommended. When $\mathrm{NHS}$ was conducted, a report containing both initial and rescreen NHS results was sent to the pediatrician concerned in order to encourage caregiver follow-up compliance and to facilitate a collaborative approach to NHS. If another unilateral or bilateral refer was recorded at the rescreen, immittance measures, including high frequency tympanometry, were conducted immediately. If abnormal immittance measures were obtained, referral to an otolaryngologist and/or pediatrician was recommended, followed by a rescreen after medical management. A diagnostic audiological evaluation was scheduled as soon as possible if normal immittance measures in conjunction with a refer result were obtained in one or both ears during the rescreen. The process of data collection was as follows:

- Informed consent was obtained from the owner of the private hospitals to access the retrospective hearing screening record forms and to make use of this information, on a private and confidential basis (Appendix $A$ ).

- Once ethical clearance had been granted, the researcher went to each private hospital and drew the archived hearing screening record forms from May 2007 until December 2009 (Hospital A), and from July 2007 until December 2009 (Hospital B).

- The researcher documented the relevant data from the hearing screening record forms on the data collection form she had designed for this purpose (Appendix $\mathrm{C}$ ).

- Once the researcher had recorded the relevant data, the hearing screening record forms were returned to the archives of the private hospitals.

- The data collection forms were subsequently saved in electronic format for later archiving and data analysis at the University of Pretoria. 


\subsubsection{Surveys of screen refusal (Study II) and follow-up default (Study III)}

\section{Research population}

The sub-component of the study included two samples of caregivers. The first sample comprised 25 caregivers who had declined to participate in the NHS programme. The second sample was made up of 25 caregivers who had not returned for a recommended follow-up hearing screening after the initial screening. Only participants from Hospital B were included in these two surveys as more participants had been recorded at this hospital and there was a higher rate of screen decline and follow-up default than at Hospital A.

\section{Research sample}

For this sub-component of the study, which used a telephonic survey, two research sample groups were included, namely:

a) Research sample Group one: 25 randomly selected caregivers who had declined hearing screening for their infants

b) Research sample Group two: 25 randomly selected caregivers who had defaulted on follow-up

A purposive sampling method was used during this sub-component of the study as two particular groups of people were selected to represent diverse perspectives on the reasons for screen refusal and follow-up default (Leedy \& Omrod, 2005). Of the two sample groups purposively selected, 25 participants were randomly selected from each group so that each member of the group had an equal chance of being selected. This is a reliable method of ensuring the representativeness of the samples (De Vos, Strydom, Fouché \& Delport, 2005).

Participants were all mothers, with an average age of 29.8 years ( $\pm 5.7 \mathrm{SD}$ ) in the screen refusal group and 29.3 years ( $\pm 5.6 \mathrm{SD}$ ) in the follow-up default group. Almost all participants (96\%) had private medical insurance. Infant birth dates ranged from June 2008 to December 2009 and interviews were conducted between November 2011 and June 2012.

\section{Data collection material and apparatus}

In order to collect data for the sub-component of the study, participants were identified and information was collected from them verbally through the use of two short telephonic surveys; the survey for Group one investigated the caregiver reasons for screen refusal (Appendix D), while the survey for Group two investigated the caregiver reasons for followup default (Appendix E). 
The participants were contacted telephonically and interviewed using 12 partially openended questions designed specifically for each group. The questions each provided a set of dichotomous and nominal closed-ended response options as well as an open-ended response option. The researcher and a trained research assistant conducted these surveys. The interviewer indicated the participant response with an " $X$ " in the appropriate response box and transcribed participants' open-ended responses where these were given.

A letter of informed consent attached to both surveys was read to the participants and verbal informed consent was indicated in the appropriate response box. If participants declined to participate, they were asked to offer their reasons for doing so.

Telephonic survey: reasons for screen refusal (Appendix D)

This survey consisted of four sections: demographic information, caregiver knowledge of NHS (NHS), initial test and one-year follow-up. These are discussed below:

\section{- Section A: Demographic information}

Each participant was allocated a participant code. Infant and maternal demographic information was collected from the data that had previously been recorded on the hearing screening record form and recorded on the telephonic survey data collection form. This information comprised infant birth date, sex, birth weight, APGAR scores (at 1 and 5 minutes), birth type, pregnancy duration, maternal age and possible risk factors, and included whether the infant had been admitted to the NICU. The name of the medical aid was noted where the infant and caregiver had made use of one. The private hospital and location of the initial test were recorded as well as the result of the initial hearing screening test.

\section{- Section B: Caregiver knowledge of NHS}

Questions investigating where the caregiver had received information regarding NHS were included in this section. The researcher determined whether an audiologist had approached the caregiver informing her of NHS, whether the caregiver had received any written information of NHS and been given the private hospital contact details, and whether the caregiver was aware of the negative impact a hearing loss could have on a child's development. 


\section{- Section C: Initial test}

If the caregiver had been aware of the recommended hearing screening, then the reason for screen refusal was established. The likelihood of agreeing to NHS if it were included in the hospitalisation package and/or covered by medical aid was determined.

\section{- Section D: One-year follow-up}

The researcher established whether the caregiver had been aware of the recommended follow-up retest at one year of age. The caregiver was again offered the opportunity to bring their infant for hearing screening. If the caregiver had declined this offer, the reason for screen refusal was again established. The caregiver was given the opportunity to make a comment.

\section{Telephonic survey: reason for follow-up default (Appendix E)}

This survey consisted of four sections: demographic information, caregiver knowledge of $\mathrm{NHS}$ (NHS), initial test and follow-up retest and one-year follow-up as discussed below:

\section{- Section A: Demographic information}

Each participant was allocated a participant code. Infant and maternal demographic information was collected from the data previously recorded on the hearing screening record form and entered on the telephonic survey data collection form. Information comprised infant birth date, sex, birth weight, APGAR scores (at 1 and 5 minutes), birth type, pregnancy duration, maternal age and possible risk factors, including whether the infant had been admitted to the NICU. The name of the medical aid was noted in cases where the infant and caregiver had made use of one. The private hospital where the hearing screening had been offered was recorded.

\section{- Section B: Caregiver knowledge of NHS}

Questions investigating if and where the caregiver had received information about NHS were included in this section. The researcher determined whether an audiologist had approached the caregiver informing her of NHS, whether the caregiver had received any written information of NHS and the contact details of the private hospital, and whether the caregiver was aware of the negative impact a hearing loss could have on a child's development.

\section{- Section C: Initial test and follow-up retest}

As the caregivers had given consent to have their infants' hearing screened, they were asked whether they were aware of the test results and the follow-up retest that had been 
subsequently recommended. If the caregiver was aware of the follow-up retest recommendation, the researcher established how this recommendation had been conveyed to her and the reason/s for the caregiver's failure to take the child for the follow-up retest.

\section{- Section D: Follow-up test}

The researcher established whether the caregiver had been aware of the recommended follow-up retest at one year of age and whether she would have liked to bring her child to the hospital for retesting. If the caregiver had declined this one year follow-up, the reason for refusal was established. The caregiver was given the opportunity to make a comment.

\section{Data collection procedure}

The data collection procedure for the sub-components (Study II and Study III) of the study was as follows:

- Informed consent was obtained from the owner of the private practices to access the retrospective hearing screening record forms and to make use of this information, on a private and confidential basis (Appendix $A$ ).

- Once ethical clearance had been granted, the researcher went to each private hospital and drew the archived hearing screening record forms from the last 31 to 33 months.

- The researcher randomly selected 25 caregivers who had declined hearing screening for their infants and 25 caregivers who had defaulted on follow-up hearing screening over the past 31 to 33 months from Hospital B.

- Telephone numbers were obtained from the hearing screening record forms.

- The researcher or trained research assistant contacted the caregivers telephonically on weekdays between 17:30 and 18:30.

- The letter of informed consent was read to the caregiver and informed consent was obtained verbally before the survey commenced. Willingness to participate was indicated by the researcher or research assistant on the telephonic survey form (Appendix D and Appendix E) by marking the appropriate box with an ' $X$ '.

- If the caregiver declined participation, her reason for doing so was established, the caregiver was thanked for her time and the telephonic contact was ended.

- If the caregiver agreed to participate, the questions listed on the survey form were asked. The interview lasted between 12 and 15 minutes. 
- Participant responses were indicated on the telephonic survey form either by marking the appropriate box allocated to each answer with an ' $X$ ' or by transcribing participant responses.

- Once the researcher had recorded the relevant data, the hearing screening record form was returned to the archives at the private hospitals.

- The data collection forms have subsequently been saved in electronic format for later archiving and data analysis at the University of Pretoria.

\subsection{Data processing and analysis procedure}

Data gathered were quantitative in nature and documented directly onto a data collection form (Appendix C) and a telephonic survey form (Appendix D and Appendix E) using Microsoft Word 2007. Data were organised in an Access Database using MS Access 2007. All information from this database was converted to a Microsoft Excel data sheet. A qualified statistician was employed to assist with statistical analysis using the statistical analysis software, SPSS versions 19.0 and 20.0.

Descriptive statistical measures were used to describe and summarise the general nature of the data obtained. Measures included data correlation, data variability and measuring the point of central tendency (Leedy \& Omrod, 2005). Data were statistically analysed to yield percentages and frequency distributions. Statistical procedures such as Chi-Squared and, where appropriate, Fisher's Exact tests were administered. Frequency and cross-tabulations were compiled to describe the sample according to coverage, referral rate, follow-up rate and to make comparisons in coverage, referral and follow-up rates between the two private hospitals.

Inferential statistics were used to allow the researcher to make deductions about a large population from a relatively small sample (Leedy \& Omrod, 2005). Measures were used to assess the significance of a number of variables on the data obtained and to establish whether any statistically significant relationships existed within the data (Leedy \& Omrod, 2005). The researcher actively interpreted the collected data: it was perused to get a sense of what it contained as a whole, then general categories and themes were extracted and relationships were described to find meaning in the data. Tables and figures were constructed to offer a hypothesis and to synthesise the overall findings. 


\subsection{Validity and reliability}

Validity and reliability influence the extent to which the researcher will be able to draw conclusions from the data collected, the statistical significance of the data analysis and the meaningfulness of the phenomenon in question (Leedy \& Omrod, 2005). Validity errors reflect bias in the measurement instrument itself and reliability errors reflect errors in the use of the measurement instrument (Leedy \& Omrod, 2005).

In order to avoid these errors the researcher ensured the trustworthiness of the quantitative data collected by taking the following precautions:

- NHS was conducted in more than one private hospital. This increased the credibility and transferability of the data because NHS was conducted in more than one setting.

- NHS was conducted on two separate occasions where necessary. This increased the test-retest reliability of the measurement instrument (Leedy \& Omrod, 2005).

- Data were collected in a real life setting allowing for conclusions to be generalised to other contexts and strengthening the validity of the study (Leedy \& Omrod, 2005).

- The participants who were enrolled in the NHS programme at two private hospitals in the Western Cape and those who participated in the telephonic survey were a representative sample of the population, thereby strengthening the validity of the study (Leedy \& Omrod, 2005).

- The audiological equipment that was used in the data collection is calibrated annually to ensure accurate and reliable results.

- Only trained and qualified audiologists carried out NHS, thus ensuring reliable data collection as there was standardisation in the use of equipment between one situation or user and the next (Leedy \& Omrod, 2005).

- No subjective interpretation of the OAE results was necessary as the 'pass' and 'refer' criteria are predetermined by the equipment software thereby increasing interpreter reliability and the reliability of the measurement instrument (Leedy \& Omrod, 2005).

- During the data collection process in the telephonic survey, the researcher avoided interviewer bias by posing the survey questions in a neutral manner and in the same way for each participant (Mrug, 2010).

- Sampling bias occurred as not all individuals had a telephone and many who did screened their calls using caller ID and answering machines. Respondents might also have been unwilling to answer questions over the telephone. However, 
individuals might have been more likely to respond to a telephonic survey than to a questionnaire sent to them in the post (Mrug, 2010).

- The researcher compared multiple data sources in search of common themes to support the validity of the qualitative findings. She consulted with the co-researchers to ensure that she had made appropriate interpretations and reached valid conclusions from the data. The researcher described the findings in sufficient detail for readers to draw their own conclusions from the findings. These approaches supported the validity of the qualitative findings (Leedy \& Omrod, 2005). 


\section{RESEARCH ARTICLE}

\section{TITLE: WHY PARENTS REFUSE NEWBORN HEARING SCREENING AND DEFAULT ON FOLLOW-UP RESCREENING - A SOUTH AFRICAN PERSPECTIVE}

Authors: Lucia Jane Scheepers, De Wet Swanepoel and Talita Le Roux

Journal: Journal of Pediatric Otorhinolaryngology

Accepted: 22 January 2014

Publication: Online electronic publication ahead of print: 31 January 2014, http://dx.doi.org/10.1016/j.jpporl.2014.01.026

Note: This article was edited in accordance with the editorial specifications of the journal and may differ from the editorial style of the rest of this document.

\subsection{ABSTRACT}

Objectives: This study describes screen refusal and follow-up default characteristics together with caregiver reasons for screen refusal and follow-up default in two South African universal newborn hearing screening programs.

Methods: A retrospective record review of universal newborn hearing screening conducted at two hospitals (Hospital A $n=954$ infants; Hospital B $n=2135$ ) over a 31 to 33 month period. Otoacoustic emission screening was conducted with rescreen recommended within six weeks for a uni- or bilateral refer. Program efficacy was described according to coverage, referral and follow-up rates. A prospective telephonic interview with caregivers who declined the initial screen $(n=25)$ and who defaulted on follow-up $(n=25)$ constituted the next study component. Caregivers were randomly selected from the screening programs for a survey related to reasons for newborn hearing screening refusal and follow-up default.

Results: Screening coverage (89.3\% Hospital A; 57.4\% Hospital B), initial referral rates (11.6\% Hospital $A ; 21.2 \%$ Hospital $B$ ) and follow-up return rates (56.1\% Hospital $A ; 35.8 \%$ Hospital B) differed significantly between hospitals and were below benchmarks. The most frequent reasons for screen refusal were related to costs $(72 \%)$, caregiver knowledge of newborn hearing screening (64\%) and health care professional knowledge and team collaboration (16\%). Almost all caregivers (96\%) indicated that if costs had been included in the birthing package or covered by medical insurance they would have agreed to newborn hearing screening. Reasons for follow-up default were most commonly related to caregiver knowledge of newborn hearing screening (32\%) and costs (28\%). One in four caregivers (24\%) defaulted on follow-up because they forgot to bring their infant for a rescreen. Only 
half of caregivers (48\%) who defaulted on follow-up reported being aware of initial screen results while $60 \%$ reported being aware of the recommended follow-up rescreen.

Conclusion: Caregivers most commonly refused screening due to associated costs and mostly defaulted on follow-up due to an apparent lack of knowledge regarding initial screen outcome and recommendations made for follow-up. Including NHS as a mandated birthing service is essential if coverage is to be increased, while reducing follow-up defaults requires proactive reminders and improved communication with caregivers.

Keywords: Universal newborn hearing screening; Early hearing detection and intervention; Distortion product otoacoustic emissions; Coverage; Screen refusal; Follow-up default

Abbreviations: NHS, newborn hearing screening; EHDI, early hearing detection and intervention.

\subsection{INTRODUCTION}

Despite the demonstrated advantages of newborn hearing screening (NHS) for optimal outcomes in infants with hearing loss (Moeller, 2003; Yoshinaga-Itano \& Apuzzo, 1998; Yoshinaga-Itano, Sedey \& Coulter et al., 1998), it is still not legislated or mandated in South Africa. The absence of legislation together with a lack of awareness of the importance of NHS in South Africa means that initial detection of hearing loss is typically delayed, with average ages of first diagnosis ranging from 23 to 42 months of age (Swanepoel, Johl \& Pienaar, 2013; Swanepoel, Störbeck \& Friedland, 2009; Theunissen \& Swanepoel, 2008; Van der Spuy \& Pottas, 2008).

The South African health care system consists of a state run and taxpayer-funded public health care sector and a private sector, which caters for those individuals covered by private medical insurance or those who pay for care themselves. It is estimated that $16 \%$ to $45 \%$ of the population access private health care and between $55 \%$ and $84 \%$ use public health care facilities (Biermann, 2006). Only $27 \%$ and $53 \%$ of hospitals in the public and private health care sectors respectively offer NHS services (Meyer, Swanepoel, le Roux \& van der Linde, 2012; Theunissen \& Swanepoel, 2008), with true NHS being offered by only $14 \%$ of hospitals in the private health sector (Meyer, Swanepoel, le Roux \& van der Linde, 2012).

The shortage of NHS services in the private health sector and their unsystematic nature have been attributed to several factors: the omission of NHS services from hospital birthing packages, health care institutional policy and the lack of reimbursement to individuals by medical insurance (Meyer \& Swanepoel, 2011; Meyer, Swanepoel, le Roux \& van der Linde, 2012). These obstacles are compounded by a lack of awareness of the importance of NHS 
among other health care professionals (Meyer \& Swanepoel, 2011). In the public health care sector, the situation is exacerbated by inadequate equipment and training and staff shortages (Theunissen \& Swanepoel, 2008). As a result, it is estimated that more than $90 \%$ of infants born in South Africa will not have access to NHS (Theunissen \& Swanepoel, 2008).

In the private health sector, NHS is mostly dependent on individual initiatives by private audiologists. The service remains unstructured, unsystematic and available only in certain hospitals (Swanepoel, Störbeck \& Friedland, 2009). Since NHS becomes an additional service that is often an out-of-pocket expense, concerns regarding costs may influence screen refusal and poor uptake of services (Swanepoel, Ebrahim \& Joseph et al., 2007). Screen refusal and coverage are also influenced by caregiver knowledge and attitudes towards NHS (Olusanya, Luxon \& Wirz, 2004a), both of which could be improved through support of NHS by medical professionals involved in the newborn's care (Moeller, White \& Shisler, 2006).

Together with the lack of NHS coverage and caregiver screen refusal, the failure of caregivers to bring their infants for follow-up rescreen after an initial NHS refer result also contributes to delayed identification and intervention of hearing loss. To date, NHS follow-up return rates in both the private and public health care sectors of South Africa have failed to meet the recommended minimum of more than 70\% (HPCSA, 2007). A minority (28\%) of existing hospital-based NHS programs in the private health care sector meet national and international benchmarks for follow-up (HPCSA, 2007; JCIH, 2007; Meyer, Swanepoel, le Roux \& van der Linde, 2012).

Globally, poor follow-up return rates among infants who have failed NHS also remain a major challenge to existing programs (Olusanya et al., 2007). Reports from Nigeria have indicated inadequate follow-up returns rates for second stage screening at both clinic (48.1\%) and hospital-based (16\%) levels (Olusanya, 2009; Olusanya \& Akinyemi, 2009; Olusanya, Wirz \& Luxon, 2008). Further afield in the USA, a national review of early hearing detection and intervention (EHDI) programs revealed that although national coverage is reported to be $>95 \%$, almost half of those with initial referrals (46.1\%) are lost to follow-up (Gaffney, Eichwald, Grosse \& Mason, 2010). The lack of timely follow-up contributes to delays in diagnosis and intervention of hearing loss and may have a detrimental impact on childhood development and later academic achievement (Olusanya, 2007). 
Since screen refusal and follow-up default are major barriers to the success of NHS programs (Tann et al., 2009) in South Africa, this study investigated caregiver reasons for screen refusal and follow-up default in two private health care hospital-based universal newborn hearing screening programs.

\subsection{METHOD}

Institutional review board approval was obtained before any data collection commenced. The investigation consisted of three components: a retrospective record review of two NHS programs (Study I), a prospective survey of reasons for screen refusal (Study II) and followup default (Study III).

\subsubsection{Research context}

This study was conducted at two private health care hospitals in different areas of the Western Cape Province, South Africa. The hospitals fall under the same municipality of the Western Cape region, however, according to the most recent census, the demographics of these hospitals differ considerably (City of Cape Town, 2011; Statistics South Africa, 2001). Hospital A serves an area of $110.8 \mathrm{~km}^{2}$ and a community with a population of 33448 people, of whom $76 \%$ are white, $12.1 \%$ black African and $8.4 \%$ colored (City of Cape Town, 2011; Statistics South Africa, 2001). English is the most commonly spoken language (68.4\%), followed by Afrikaans (19.8\%) (Statistics South Africa, 2001). Hospital B serves an area of $20.5 \mathrm{~km}^{2}$ and a community with a population of 43288 people, $65.2 \%$ of whom are colored, $18.1 \%$ black African and 14.8\% white (Statistics South Africa, 2001, City of Cape Town, 2011). Afrikaans is the most commonly spoken language (67.6\%), followed by English (24.2\%) (Statistics South Africa, 2001).

\subsubsection{NHS retrospective record review - Study I}

\section{Study population}

Files of infants enrolled over a 31 to 33 month period were reviewed and processed electronically. Results of the NHS program at Hospital A were reported from May 2007 until December 2009, and from July 2007 until December 2009 at Hospital B. Hospital A included 954 infants over this period while Hospital B included 2135 infants.

\section{Protocol and methods}

Audiologists employed by the private practice situated at each hospital conducted the screening daily, except on Sundays. Automated Distortion product otoacoustic emissions were used for screening (Biologic AuDx). Screening parameters included the evaluation of 
the frequencies from 2, 3, 4 and $5 \mathrm{kHz}$ using a 65/55dB SPL stimulus level (L1/L2). Three of the four frequencies were required for the infant to pass, with a minimum distortion product amplitude of $-8 \mathrm{~dB}$ and a minimum signal-to-noise ratio of $6 \mathrm{~dB}$ for an overall pass result.

Caregivers were approached one to three days after the birth of the infant, prior to discharge. NHS was explained to the caregiver and subsequently offered as a fee-based service. If caregivers were discharged before being offered the hearing screening they were contacted telephonically and informed of the NHS service. Only infants from the well-baby nurseries were included in this study. Written consent was required from caregivers before hearing screening could proceed. Record was kept of every infant enrolled in the NHS program, whether the respective caregiver had declined or agreed to the hearing screening. This hard copy record form included demographic information and hearing screening results if hearing screening had been conducted.

At both hospitals, infants were screened in the nursery, at the caregiver's bedside or in the audiology private practice situated inside the hospital building and in a room with acceptably low noise levels. The NHS program protocol was based on the guidelines provided by the Health Professions Council of South Africa Year 2007 position statement on EHDI for South Africa (HPCSA, 2007). If the hearing screening yielded a unilateral or bilateral refer, a rescreen within six weeks of the first screen was recommended. Caregivers were required to arrange a convenient appointment date and to bring the infant to the audiology private practice for this rescreen. An information leaflet was provided to all caregivers, providing general information on NHS and the contact details of the audiology practice. A sticker was placed in the infant's clinic card and hospital file indicating the practice's contact details and whether NHS had been declined, passed or a rescreen recommended. When NHS was conducted a report containing both initial and rescreen NHS results was sent to the pediatrician concerned in order to encourage caregiver follow-up compliance and to facilitate a collaborative approach to NHS. If another unilateral or bilateral refer was recorded at the rescreen, immittance measures, including high frequency tympanometry, were conducted immediately. If abnormal immittance measures were obtained, referral to an otolaryngologist and/or pediatrician was recommended, followed by a rescreen after medical management. A diagnostic audiological evaluation was scheduled as soon as possible if normal immittance measures in conjunction with a refer result were obtained in one or both ears during the rescreen. 


\section{Data management and analysis}

Information from the participants' record forms was captured in an electronic database and subsequently analyzed using a statistical package (SPSS versions 19.0 and 20.0). The retrospective data was analyzed using descriptive and inferential statistics, including the independent samples t-test with a $1 \%$ level of significance. Frequency distributions and other descriptive measures such as the mean, median and standard deviation were used to describe the results. The efficacy of the NHS programs at the two hospitals are described according to the screening and follow-up characteristics, coverage and referral rates.

\subsubsection{Surveys of screen refusal (Study II) and follow-up default (Study III)}

The second and third component of this study comprised a prospective telephonic interview with caregivers who had declined the initial hospital screen (Study II) and who defaulted on follow-up (Study III). Twenty-five caregivers who declined hearing screening for their infants and 25 who did not bring their infants for a follow-up rescreen at or before six weeks of age were selected, using a non-probability quota sampling method. Information was elicited from participants through a partially open-ended interview schedule. Only participants from Hospital B were included in these two surveys as more participants were recorded at this hospital and there was a higher rate of screen decline and follow-up default than at Hospital A.

\section{Study population}

Participants were mothers with an average age of 29.8 years $( \pm 5.7 \mathrm{SD})$ in the screen refusal group and 29.3 years $( \pm 5.6$ SD) in the follow-up default group. Almost all (96\%) participants had private medical insurance. Infant birth dates ranged from June 2008 to December 2009 and interviews were conducted between November 2011 and June 2012.

\section{Protocol and methods}

Telephone numbers of caregivers were obtained from the infant record forms. Participants were contacted telephonically on weekdays between 17:30 and 18:30. Informed consent was obtained verbally from the caregivers before the interview commenced.

The interview survey for screen refusal consisted of four sections (demographic information, caregiver knowledge of NHS, initial test and follow-up rescreen), containing in total 12 partially open-ended questions. The interview survey for follow-up default also comprised four sections (demographic information, caregiver knowledge of NHS, initial and follow-up rescreen and one year follow-up), composed of a total of 11 partially open-ended questions. 
The researcher and a trained research assistant conducted the interviews, which lasted on average between 12 and 15 minutes.

\section{Data management and analysis}

Responses were recorded on data collection forms and transferred to an electronic database before being analyzed using the statistical package SPSS (versions 19.0 and 20.0). Descriptive statistical analysis was employed to determine frequency distributions, means and standard deviations. The Fisher's Exact and Chi-Squared tests were conducted to determine statistically significant relationships between variables.

\subsection{RESULTS}

\subsubsection{NHS retrospective record review - Study I}

There were 954 infants from Hospital A and 2135 from Hospital $B$. The mean age of the infants from Hospital A was 3.1 days ( $\pm 11.3 \mathrm{SD}$ ), and 1.8 days $( \pm 1.0 \mathrm{SD})$ at Hospital $B$. Almost all the caregivers of the infants concerned had private medical insurance $(99.8 \%$ for Hospital A and $98 \%$ for Hospital B).

Very few (10\%) caregivers from Hospital A who were offered NHS declined the service, while at Hospital B just under half (42.5\%) declined NHS. The initial referral rate for Hospital A was $11.6 \%$ and for Hospital B, 21.2\% (Figure 1). Follow-up return rates were $56.1 \%$ for Hospital A and $35.8 \%$ for Hospital B (Figure 1).

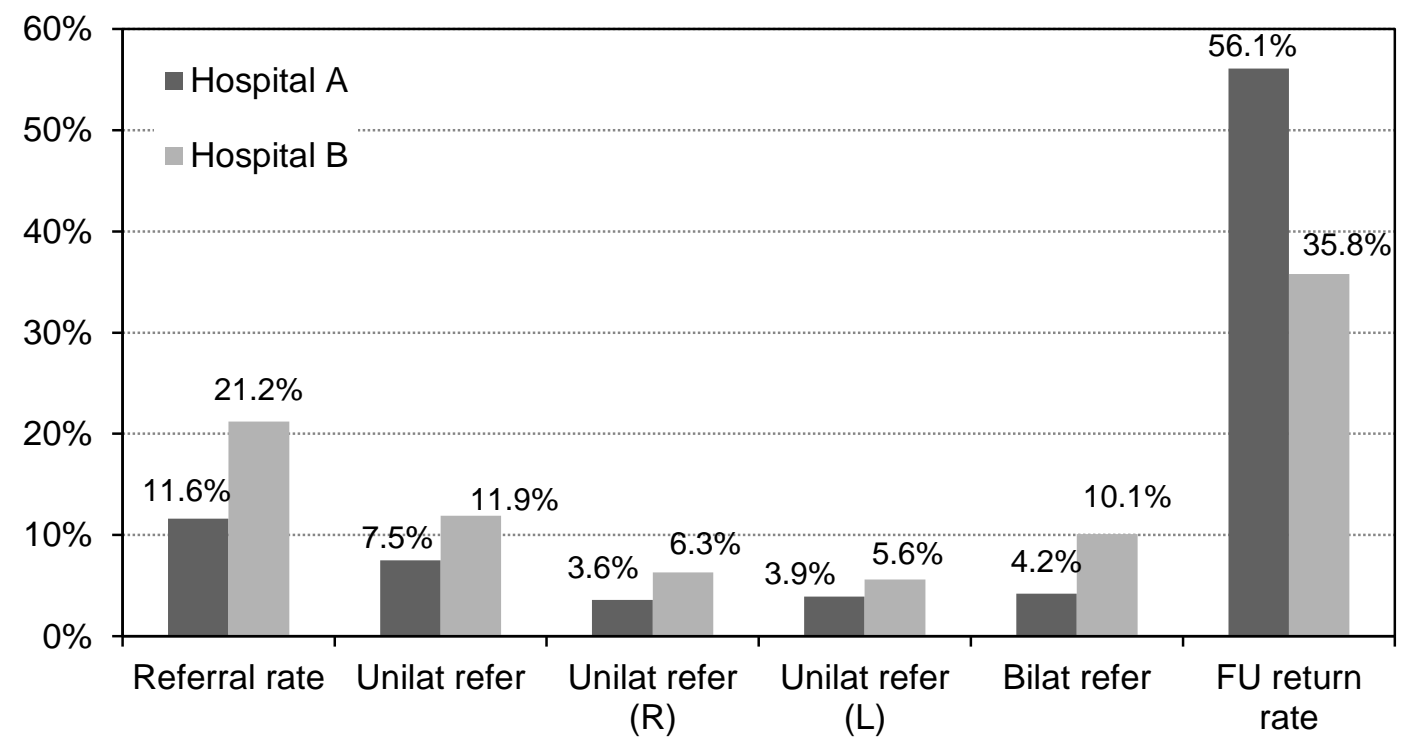

Figure 1. Newborn hearing screening referral rate and follow-up return rate Unilat = Unilateral; Bilat = Bilateral; $R=$ Right; $L=$ Left; FU = Follow-up 
There was a statistically significant difference (Fisher's Exact test; $p<0.0001$ ) between the age of infants who failed the initial screen (1.7 days; $1.3 \mathrm{SD} ; \mathrm{n}=91$ ) and those who passed (3.5 days; 12.4 SD; $n=690$ ) at Hospital A (Figure 2). Results for Hospital B also revealed a significant difference (Fisher's Exact test; $p<0.0001$ ) between the age of infants who failed the screen (1.6 days; 0.6 SD; $n=252$ ) and those who passed ( 1.9 day; $1.3 \mathrm{SD} ; n=925)$. There was no statistically significant effect of the duration of program existence (Chi-squared test; $p>0.05$ ) or birth weight (Fisher's Exact test; $p>0.01$ ) on the referral rate.

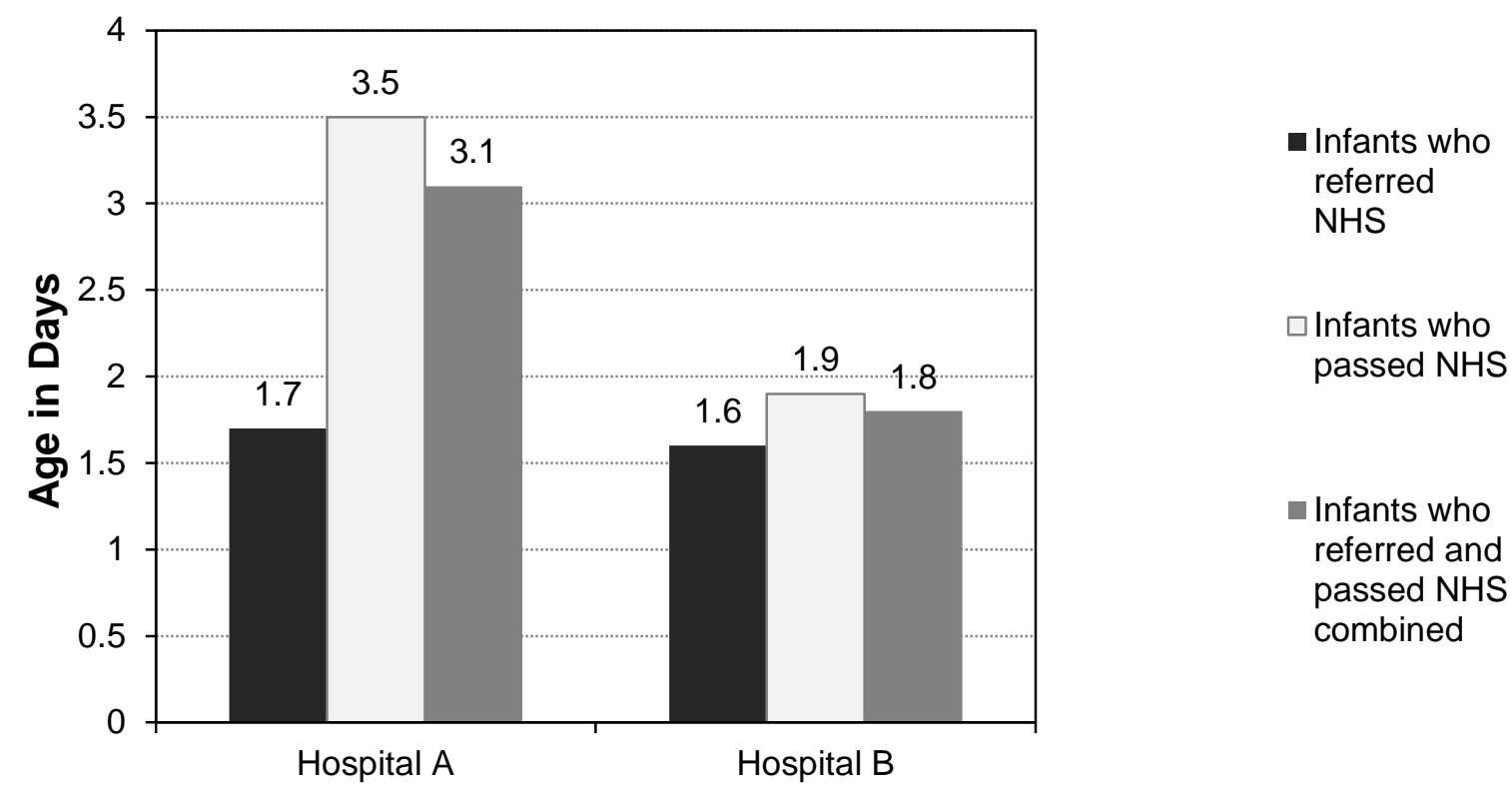

Figure 2. Average age of infants who passed or referred (unilateral and bilateral) newborn hearing screening

\subsubsection{Screen refusal survey - Study II}

The reason most commonly given by caregivers for screen refusal was the failure of medical insurance to cover the costs $(52 \%)$, followed by the perception that such screening was unnecessary $(32 \%)$ (Table 1). Caregivers were able to select more than one reason for declining NHS. 
Table 1. Caregivers' reasons for declining the NHS screen $(n=25)$

\begin{tabular}{ll}
\hline Reason for screen refusal & Frequency \\
\hline Medical insurance does not cover cost & $52 \%$ \\
Not necessary & $32 \%$ \\
Not enough information received prior to the birth & $24 \%$ \\
Not included in the hospital birthing package & $20 \%$ \\
Not recommended by the pediatrician & $16 \%$ \\
Unsure & $8 \%$ \\
Consult with family first & $4 \%$ \\
Caregiver forgot & $4 \%$ \\
\hline
\end{tabular}

Just over a third of caregivers (36\%) who were surveyed indicated prior knowledge of the fact that a baby's hearing can be tested soon after birth. Of this group, $20 \%$ had received information on NHS at the time of the birth of an earlier child, while $16 \%$ received information from a pediatrician. Only $40 \%$ of respondents thought that NHS was reliable, with the majority $(60 \%)$ unsure.

Almost all caregivers (88\%) reported that NHS was important (Figure 3). Although $20 \%$ of caregivers indicated that they did not think effective treatment or intervention was available for infants identified with permanent hearing loss, and half (48\%) were unsure about this, almost all (96\%) caregivers indicated that they would have agreed to hearing screening if it had been included in the cost of the birthing package or if their private medical insurance covered the costs. 


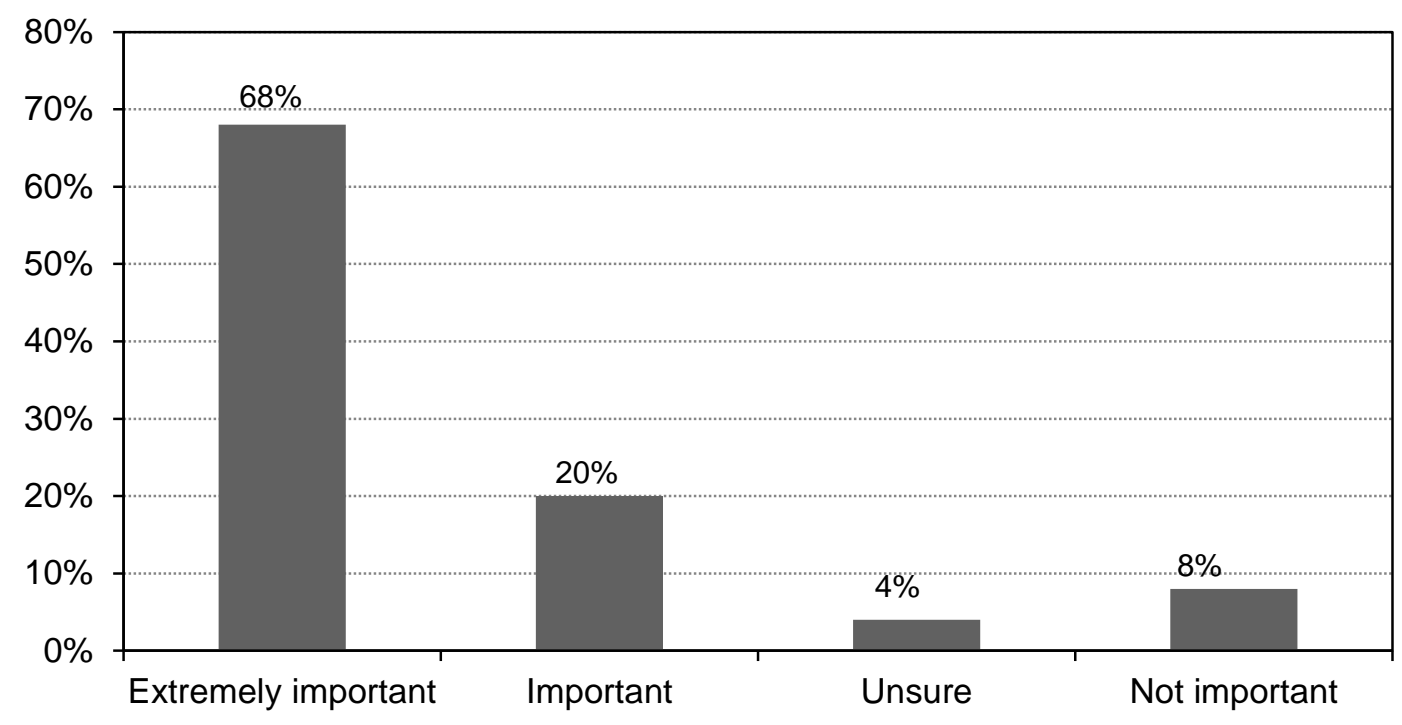

Figure 3. NHS importance as perceived by caregivers who refused hearing screening $(n=25)$

Just over a third of caregivers (36\%) reported having received written information regarding $\mathrm{NHS}$ when the screen was offered to them. Of the caregivers who received this information, the majority $(77.8 \%)$ reported that NHS was extremely important although most of this group $(77.8 \%)$ were uncertain of its reliability. One third $(33.3 \%)$ of this group believed that there was effective treatment available for infants born with a permanent hearing loss. Almost half (44.4\%) of the caregivers who received written information regarding NHS indicated that an audiologist was the person responsible for NHS, whilst $44.4 \%$ indicated that the responsible professional was the pediatrician. The remainder (11.1\%) believed that the caregiver was primarily responsible for NHS. There was no statistically significant effect of maternal age on the rate of screen refusal (Fisher's Exact test; $p<0.0001$ ).

\subsubsection{Follow-up default survey - Study III}

The reasons given most frequently for follow-up default were caregivers' perceptions that follow-up was unnecessary (32\%), and the fact that they had forgotten about the follow-up (24\%) (Table 2). Caregivers were able to select more than one reason for follow-up default. 
Table 2. Caregivers' reasons for defaulting on follow-up appointment $(n=25)$

\begin{tabular}{ll}
\hline Reason for follow-up default & Frequency \\
\hline Not necessary & $32 \%$ \\
Caregiver forgot & $24 \%$ \\
Unaware re-test costs were included in initial cost & $20 \%$ \\
Re-test not recommended by pediatrician & $12 \%$ \\
Medical insurance did not cover cost of initial test & $8 \%$ \\
Caregiver unable to bring infant owing to work commitments & $8 \%$ \\
No transport & $4 \%$ \\
\hline
\end{tabular}

Almost all caregivers (96\%) reported having received information regarding NHS while they were still in hospital after the birth of their infant. The majority $(80 \%)$ received this information from an audiologist or from nurses (8\%), from pediatricians (4\%), gynecologists (4\%) or others $(4 \%)$. Most $(80 \%)$ of the caregivers reported having received an information pamphlet on NHS, outlining its importance and providing the audiology practice's contact details.

Despite almost all caregivers (96\%) indicating that they believed that early detection of hearing loss was extremely important, only $56 \%$ believed that there was effective treatment and intervention for infants born with a permanent hearing loss. Only $8 \%$ thought that no treatments are available while $36 \%$ were unsure.

Almost half of the caregivers (48\%) reported being aware of the hearing screening outcome, while $48 \%$ were apparently unaware of this, and $4 \%$ were unsure. The majority $(60 \%)$ of caregivers reported being aware of the recommendation to bring their child back for a followup re-test after six weeks, but $36 \%$ were apparently unaware of this (4\% were unsure). Of those who indicated being aware of the six week follow-up recommendation, most (44\%) attributed this to a discussion with the audiologist, while others $(36 \%)$ attributed it to the sticker placed in the infant's clinic card by the audiologist, recommending the follow-up. No caregivers reported being informed of the follow-up recommendation by the pediatrician or a nurse.

Just over half of caregivers (56\%) reportedly felt NHS was reliable, while $24 \%$ indicated that it was unreliable and $20 \%$ were unsure. Half of the caregivers $(48 \%)$ indicated that they would like to bring their child for a follow-up rescreen, while $44 \%$ reported that they would not want to bring their child for a rescreen as they felt it was unnecessary $(84.6 \%)$, or because their medical insurance did not cover the initial test cost $(7.7 \%)$. A small group of 
caregivers $(7.7 \%)$ was unsure whether they wished to bring their child for a follow-up rescreen or not.

The majority of caregivers $(80 \%)$ reported receiving written information regarding $\mathrm{NHS}$. Almost all $(95 \%)$ of those who had received written information indicated that NHS was extremely important and over half $(60 \%)$ felt that $\mathrm{NHS}$ was reliable. Half $(50 \%)$ felt that effective treatment of a permanent hearing loss was available, while $40 \%$ were unsure and $10 \%$ believed that no treatment was available. The majority of caregivers (85\%) who received written information about NHS felt that an audiologist was the person responsible for $\mathrm{NHS}, 10 \%$ believed it was the role of the nurse and $5 \%$ were unsure.

\subsection{DISCUSSION}

\subsubsection{NHS retrospective record review - Study I}

Screening coverage differed between hospitals (89.3\% Hospital A; 57.4\% Hospital B) and was below recommended national and international benchmarks (HPCSA, 2007; JCIH, 2007). Different demographic characteristics, including socio-economic conditions and educational levels in the two areas in which the hospitals are situated, may partly explain differences in screen coverage and rate of screen decline. Hospital A serves a more affluent and educated, predominantly white, (76\%) community while Hospital B serves a relatively socially deprived colored (65.2\%) community with lower levels of education (City of Cape Town, 2011). Higher levels of caregiver education have previously been associated with earlier diagnosis of hearing loss and initiation of intervention (Holte et al., 2012). While almost all (99.8\% Hospital A; 98\% Hospital B) caregivers had medical insurance, some schemes covered only the birthing and hospitalization costs, leaving caregivers to cover the NHS costs out of their own pockets. In a private hospital in Gauteng, South Africa (Swanepoel, Ebrahim \& Joseph, 2007), poor coverage rates were attributed to the exclusion of NHS from the birthing package. When NHS costs were included in the birthing package the coverage rate increased from $20 \%$ to $75 \%$ (Swanepoel, Ebrahim \& Joseph, 2007).

Initial referral rates of both Hospital A and Hospital B (11.6\% and $21.2 \%$ respectively) were two to four times higher than the recommended referral rate of 5\% (HPCSA, 2007; JCIH, 2007), with rates at Hospital $B$ twice as high as those at Hospital A. This may be partly attributable to the higher annual birth rate at Hospital B (2135 compared to 954 infants at Hospital A). A heavier caseload increases the pressure to test infants earlier in order to ensure all infants are tested before being discharged. This was confirmed by the lower average screen age for Hospital $B$, where infants tested were, on average, only half the age (1.8 days; $1.0 \mathrm{SD}$ ) of those tested at Hospital A (3.1 days; $11.3 \mathrm{SD}$ ). Testing younger 
newborns, predisposed as they are to residual vernix in the ear canal and amniotic fluid in the middle ear, makes them less likely to pass the NHS than older infants (Gabbard, Northern \& Yoshinaga-Itano, 1999; Lupoli, Garcia \& Anastasio et al., 2013). Referral rates that are too high place an added burden on NHS program resources and influence successful tracking and follow-up of referred infants (Yoshinaga-Itano, 2011).

Follow-up return rates at both hospitals (56.1\% Hospital A; 35.8\% Hospital B) were below recommended benchmarks (HPCSA, 2007; JCIH, 2007). Screening programs in this study relied heavily on caregivers complying with the requirement to return for follow-up rescreening; there was little or no tracking by NHS program staff. This failure to remind and encourage caregivers to comply with the recommended follow-up re-test may have affected follow-up rates adversely (Olusanya \& Akinyemi, 2009). Lack of quality control and inefficient tracking of caregivers following discharge (Meyer, Swanepoel, le Roux \& van der Linde, 2012, Swanepoel, Ebrahim \& Joseph, 2007), as well as inadequate support from other health care professionals are reasons which have been offered for the poor follow-up rates in studies conducted in the private health sector in South Africa (Meyer, Swanepoel, le Roux \& van der Linde, 2012, Swanepoel, Ebrahim \& Joseph, 2007). Satisfactory follow-up return rates have recently been reported at public health clinic and tertiary hospital level (85.1\% and $91.8 \%$ respectively) (Friderichs, Swanepoel \& Hall, 2012), however, where this success was attributed to the employment of a dedicated screening coordinator to monitor the NHS program through a system of telephone calls, home visits, training of staff and visual reminders to track participants and ensure follow-up compliance (Friderichs, Swanepoel \& Hall, 2012). In the US, satisfactory follow-up rates (94.4\%; 93.6\%) have been recorded in states that actively follow up on caregivers (Gaffney, Eichwald, Grosse \& Mason, 2010). Furthermore, follow-up rates could be improved by addressing caregiver attitudes towards the necessity and reliability of NHS (Swanepoel, 2006; Swanepoel \& Almec, 2008).

Internationally, high referral rates and sub-par follow-up return rates were also reported for hospital-based (32.3\% and $16 \%$ respectively) and immunization clinic-based $(14.3 \%$ and $48.1 \%$ respectively) NHS programs in Nigeria (Olusanya, 2009; Olusanya \& Akinyemi, 2009). A review of the average coverage and follow-up return rates across a combination of 46 developed and developing countries indicated that regional coverage $66 \%$ for high income and $1 \%$ for low income countries) falls significantly below proposed benchmarks $(\mathrm{JCIH}, 2007)$, with only the high income countries achieving follow-up rates above these benchmarks (JClH, 2007; Tann et al., 2009). 
Reported NHS coverage, referral and follow-up return rates across South Africa have been poor and to date the reasons for caregiver screen refusal and follow-up default have not been surveyed. The second part of this study investigated these reasons.

\subsubsection{NHS prospective surveys - Study II and Study III}

\section{Reasons for screen refusal}

The most frequently occurring reasons $(72 \%)$ that caregivers gave for screen refusal were cost related (52\% medical insurance does not cover cost; $20 \%$ cost not included in the hospital birthing package). Almost all (96\%) caregivers indicated that they would have agreed to NHS had the cost been included in the birthing package and/or covered by medical insurance. These findings support the inclusion of NHS costs in hospital birthing packages and medical insurance (Olusanya, 2008) with centralized data management and quality control monitoring (Meyer, Swanepoel, le Roux \& van der Linde, 2012) to improve coverage.

Other reasons given included those associated with caregiver knowledge (64\%) of $\mathrm{NHS}$ (32\% NHS not necessary; 24\% not enough information given prior to the birth; $8 \%$ unsure). In a survey of maternal views of EHDI, $99 \%$ of mothers expressed the need for more information (Swanepoel \& Almec, 2008) with clear and easily understandable written information detailing the hearing evaluation results and diagnosis (Van der Spuy \& Pottas, 2008). Findings from this study revealed that caregivers who received written information were more likely to report that NHS was extremely important $(77.8 \%)$, that effective treatment was available for permanent congenital hearing loss (33.3\%) and that an audiologist was the professional responsible for NHS (44.4\%), than those caregivers who did not receive written information. Caregiver awareness and education about NHS are vital for its successful implementation (Swanepoel \& Almec, 2008). The degree of understanding among caregivers of the importance of NHS is directly related to the level of caregiver participation (Moeller, White \& Shisler, 2006). Public awareness campaigns focusing on NHS at appropriate levels, such as at antenatal visits (Mukari, Tan \& Abdullah, 2006; Olusanya, 2008; Olusanya, 2009;), with a particular emphasis on underserved communities are therefore essential to successful NHS programs in South Africa (Holte et al., 2012).

A number of caregivers (16\%) declined NHS because their pediatrician did not recommend it. More than half $(52 \%)$ of caregivers refusing NHS believed that the pediatrician was the professional responsible for NHS (Figure 4). For these caregivers, this may have influenced screen compliance negatively as NHS was offered by the audiologist and not the 
pediatrician. This emphasizes the importance of physician support for NHS. The majority of caregivers (68\%) who agreed to NHS believed that the audiologist was the professional responsible for NHS (Figure 4). A survey of NHS in the private health sector of South Africa revealed that limited awareness of the importance of NHS among health care professionals often undermines its successful implementation (Meyer \& Swanepoel, 2011). Strengthening the medical community's knowledge and involvement, from screening to intervention, can better advocate and support NHS (Moeller, White \& Shisler, 2006). In this study, the cost of NHS, caregiver knowledge of NHS and the level of support from health care professionals involved in infant care were most influential in parental refusal of NHS.

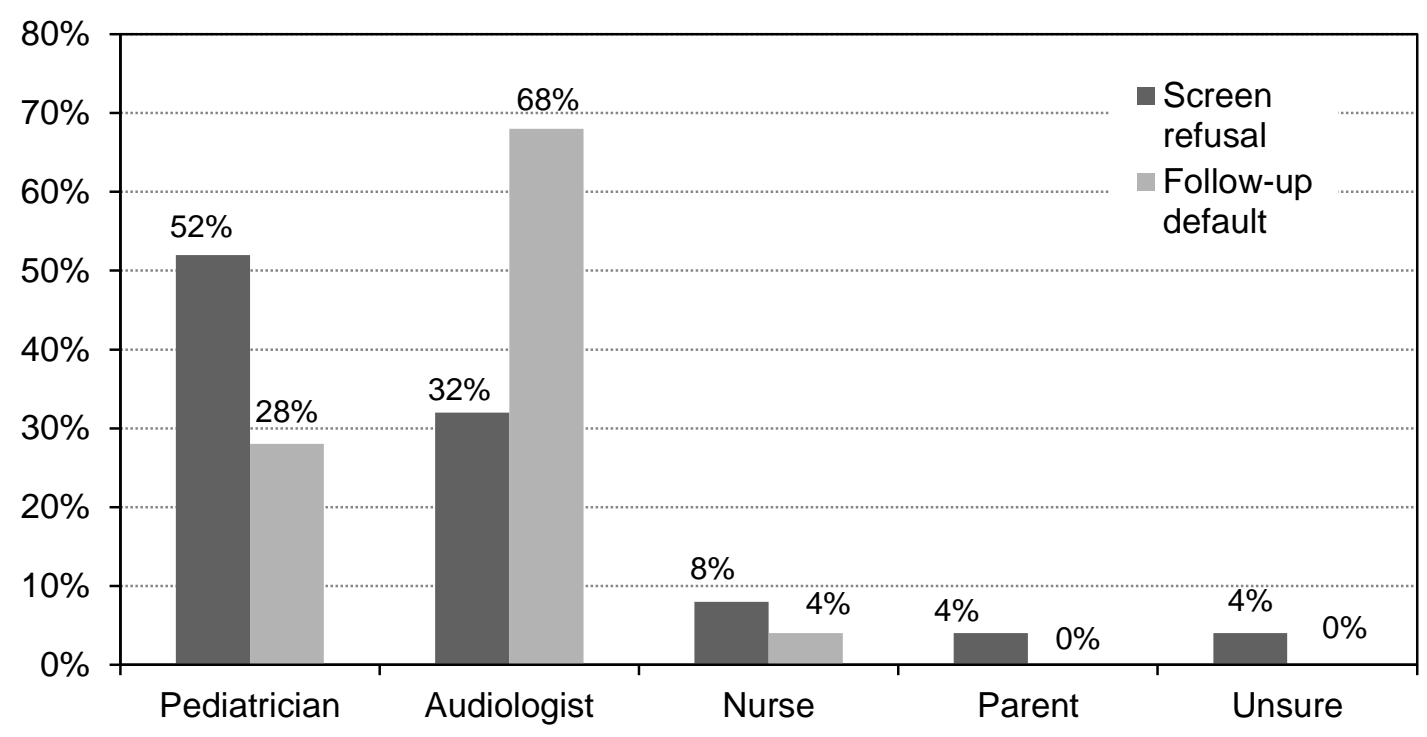

Figure 4. Person responsible for NHS as perceived by caregivers who refused NHS $(n=25)$ and who defaulted on follow-up retest $(n=25)$

\section{Reasons for follow-up default}

The reason caregivers gave most frequently for follow-up default was associated with caregiver knowledge of $\mathrm{NHS}$, with $32 \%$ indicating that they regarded follow-up rescreen as unnecessary. Only half of caregivers (48\%) who defaulted on follow-up indicated that they were aware of the screen results while only $60 \%$ indicated that they were aware of the recommended follow-up rescreen. This implies that follow-up default may have occurred in part because caregivers were unaware of or did not comprehend the screen outcome and follow-up rescreen recommendations, despite most (80\%) indicating that they had received written information regarding NHS at the initial screen. These findings emphasize the importance of effective communication with the caregiver and explanation of screen results and recommendations to this individual by the screener, accompanied by written information explaining NHS, the meaning of the screen results and the follow-up process (Holte et al., 
2012). The breakdown in clear communication of NHS results and the importance of followup interaction with the caregiver can have a negative effect on follow-up compliance (Mukari, Tan \& Abdullah, 2006; Olusanya, 2009). Although screening results and recommendations from these screening programs were conveyed to caregivers both verbally and in writing, follow-up compliance may have been enhanced had a follow-up appointment been confirmed immediately after the screen refer. Effective screener-caregiver communication must be supported by the education of caregivers regarding NHS at pre-birth opportunities (Todd, 2006).

A number of caregivers failed to return for follow-up as they were not aware that the rescreen cost was included in the initial screen cost $(20 \%)$, while others ( $8 \%)$ failed to return because their medical insurance did not cover the initial screen cost. NHS cost is therefore an important concern for caregivers and influences screen refusal as well as follow-up compliance. These findings highlight the need for NHS to be made mandatory and part of national policy in both the private and public health care sectors of South Africa. NHS costs should be included in hospitalization birthing packages and covered by medical insurance in South Africa in order to ensure effective identification and subsequent management of permanent congenital and early-onset infant hearing loss (Olusanya, 2008).

One in four caregivers (24\%) defaulted on follow-up because they forgot to bring their infant for a rescreen. Caregivers were not reminded, either telephonically or in writing, with screening programs in this study relying exclusively on caregivers' own initiative in arranging a follow-up appointment based on screen outcome. The administration of efficient data management systems and tracking protocols (Mehl \& Thomson, 2002) by dedicated personnel through the use of telephone calls and visual reminders such as text messages and emails to inform caregivers of the need to follow up (Friderichs, Swanepoel \& Hall, 2012) would facilitate and improve follow-up rescreen compliance. The immediate confirmation of a follow-up appointment date in writing following NHS would support followup compliance.

In a small number of cases (12\%), caregivers failed to bring their infants for follow-up as the pediatrician concerned did not recommend the rescreen. This emphasizes the importance of team collaboration and increased awareness of NHS and continuing professional education amongst health care professionals involved in infant care (Olusanya, 2008). A team approach is essential in facilitating the follow-up process and in reducing delays in early intervention (Holte et al., 2012). Multiple parties who are involved in the infant's care and who encourage NHS and motivate caregivers to comply with follow-up re-test 
recommendations will improve program outcomes. Lastly, logistical issues ( $8 \%$ unable to bring infant because of work commitments; $4 \%$ no transport) were cited by caregivers as reasons for defaulting on their follow-up appointments. These same logistical reasons for follow-up default were reported by some caregivers in a study in Nigeria (Olusanya, 2009) and could be addressed by scheduling a follow-up rescreen appointment immediately, to coincide with compulsory pediatric check-ups or hospital visits.

\subsection{CONCLUSION}

Issues of cost were the most common factors related to screen refusal, followed by lack of awareness of the importance and reliability of NHS among caregivers and the health care professionals involved in their infants' care. In terms of factors related to follow-up default, caregivers' lack of knowledge of screen outcome and follow-up recommendations, as well as inadequate knowledge of NHS and the NHS process were most commonly related to followup default. Findings from this study indicate that caregivers who received written information about NHS were more likely to have an accurate understanding of and positive associations with NHS. Support and education of health care professionals may best be facilitated if NHS becomes mandated hospital or birthing facility practice so that individual preferences do not overrule best practice. Centralized data management and quality control monitoring systems that include accurate tracking of referred infants through the use of text message, email and telephonic reminders by dedicated personnel are also essential to improve follow-up compliance. Screen refusal and follow-up default rates must drop if the development of ageappropriate speech and language through early identification and intervention of infants born with a hearing loss is to be facilitated.

\section{ACKNOWLEDGEMENTS}

The authors acknowledge the valued assistance of Dr Mike van der Linde, Department of Statistics, University of Pretoria, and thank the audiologists and caregivers who participated in this study. 


\section{DISCUSSION AND CONCLUSION}

\subsection{Discussion of results}

The scarcity of NHS programmes in South Africa and their poor coverage rates, together with caregiver screen refusal and loss to follow-up pose serious challenges to effective early detection of hearing loss in both the private and the public health sectors. The current study investigated these factors in the private health care sector in three sub-studies.

\subsubsection{NHS retrospective record review - Study I}

\section{Coverage and screen refusal}

Unlike developed countries, such as the US, where NHS coverage has reached $>95 \%$ (Pallarito, 2012), in South Africa only $27 \%$ of hospitals in the public health sector and $53 \%$ in the private health sector offer NHS (Meyer, Swanepoel, le Roux \& van der Linde, 2012; Theunissen \& Swanepoel, 2008), with only $14 \%$ of private sector hospitals offering UNHS (Meyer, Swanepoel, le Roux \& van der Linde, 2012). Benchmarks recommended by national and international bodies propose that within six months of initiation, a hospital-based NHS screening programme should screen $95 \%$ of infants before discharge or before one month of age (HPCSA, 2007; JCIH, 2007). Being born in a private institution that offers NHS does not guarantee that an infant will undergo NHS, however, as this is not mandated and is often for the patient or caregiver's own account, which may lead parents to decline the service. As a result, the NHS coverage rate in the private sector is significantly lower than $50 \%$ (Meyer \& Swanepoel, 2011). Screening coverage in the current study differed between hospitals (89.3\% in Hospital A; $57.4 \%$ in Hospital B) and was below the recommended national and international benchmarks (HPCSA, 2007; JCIH, 2007).

In the public health sector, coverage rates reported for NHS programmes have also been poor (32.4\%) (Friderichs, Swanepoel \& Hall, 2012). Since these services are free of charge, the low coverage rate has been attributed to staff shortages and high staff turnover (Olusanya, 2012) rather than solely to financial factors; coverage rates have been shown to be significantly higher (85.3\%) in clinics which are better staffed (Friderichs, Swanepoel \& Hall, 2012). However, funding for equipment and resources is vital in order to facilitate NHS programme implementation and sustainability (Hoffman, Muñoz, Bradham \& Nelson, 2011) and a lack of financial resources may hamper EHDI programmes in South Africa. Effective service delivery in South Africa is furthermore constrained by a scarcity of audiologists, their unequal distribution across the public and private health sectors and the fact that audiology 
in South Africa is a culturally and linguistically underrepresented profession (Swanepoel, 2006).

In order to address this skills shortage, recommendations have been made that health workers without audiological experience, such as nurses, be trained to undertake NHS (Friderichs, Swanepoel \& Hall, 2012; Hoffman, Muñoz, Bradham \& Nelson, 2011), while diagnostic and intervention services remain the domain of audiologists and ENT specialists (Olusanya, 2008; Olusanya, McPherson, Swanepoel, Shrivastav \& Chapchap, 2006). Ongoing education for audiologists and screening staff in pediatric audiology and on the importance of NHS programme implementation and data management, particularly in underserved areas, may contribute to improving EHDI in South Africa (Hoffman, Muñoz, Bradham \& Nelson, 2011; Olusanya, Luxon \& Wirz, 2004a). Although international guidelines are invaluable, training and protocols should be contextually based and designed specifically for the communities that are to be served in South Africa (Swanepoel, 2006). It is vital for the success of NHS in developing countries that context specific strategies, based on pilot studies, are developed (Olusanya, 2012).

Support from the health care community is essential if EHDI is to be successfully implemented. Participants in a survey on NHS in the private health sector in South Africa revealed that a limited awareness of the importance of EHDI among other health care professionals undermines the successful implementation of NHS (Meyer \& Swanepoel, 2011). This suggests that NHS and EHDI could be facilitated by strengthening the medical community's involvement, from screening to intervention, in a multidisciplinary framework (Moeller, White \& Shisler, 2006). Physicians (primary care gynaecologists and pediatricians) are in an ideal position to educate caregivers about EHDI and to discuss NHS results, particularly of those infants who fail the screening, and to encourage follow-up and monitoring (Moeller, White \& Shisler, 2006; Olusanya, 2012). Endorsement by the paediatrician of the necessity of follow-up retesting increases the likelihood that families will follow up the initial screening (Yoshinaga-Itano, 2011). Olusanya (2012) suggests that NHS must be seen as a component of the paediatrician's routine neonatal examination in order to facilitate prompt referral of infants requiring further evaluation. The immediate referral for NHS of high risk infants should also be routine practice (Olusanya, 2012). The detection of a hearing loss following the discharge of an infant who has been declared healthy may be grounds for professional malpractice and can be viewed as unethical, particularly in the presence of known risk factors for hearing loss (Olusanya \& Newton, 2007). 
In order to encourage support and involvement in EHDI from all health professionals, regular updates and policy statements by medical professional bodies should be introduced, as well as seminars and workshops that include nurses and midwives (Olusanya, Luxon \& Wirz, 2004a). Parents, professional bodies and the media must promote NHS to encourage its establishment in developing countries such as South Africa (Olusanya, 2012). Local associations must take the lead and support initiatives by drawing up and implementing position statements for EHDI (Olusanya, 2012). Furthermore, public-private health sector partnerships may be beneficial to the implementation of NHS nationally (Olusanya, 2012). Government and the health community must become more active in playing their part in increasing public awareness, human resource development and in establishing a regulatory framework for best practice (Olusanya, 2012).

In this study, screening coverage differed between hospitals $(89.3 \%$ at Hospital $A ; 57.4 \%$ at Hospital B) and was below the recommended national and international benchmarks (HPCSA, 2007; JCIH, 2007). Different demographic characteristics, including socioeconomic conditions (Hoffman, Muñoz, Bradham \& Nelson, 2011) and educational levels in the two areas in which the hospitals are situated may partly explain these differences in coverage and rate of screen decline. Higher levels of caregiver education have previously been associated with earlier diagnosis of hearing loss and initiation of intervention (Holte et al., 2012). Low socio-economic status and private costs associated with NHS may increase the rate of test decline, with a detrimental effect on screen coverage. A private hospital in Gauteng running a NHS programme with a poor coverage rate $(20 \%)$ attributed this to the exclusion of NHS from the birthing package (Swanepoel, Ebrahim \& Joseph et al., 2007). When the screen was included in the hospital birthing package, coverage improved significantly (75\%) (Swanepoel, Ebrahim \& Joseph et al., 2007).

Initial referral rates at both Hospital A and Hospital B (11.6\% and $21.2 \%$ respectively) were two to four times higher than the recommended referral rate of 5\% (HPCSA, 2007; JCIH, 2007), with rates at Hospital $B$ twice as high as those at Hospital A. This may be partly attributable to the higher annual birth rate at Hospital B (2135 infants compared to 954 at Hospital A). The sheer number of annual births together with a shortage of resources has a detrimental impact on UNHS in developing countries (Olusanya, 2012). A heavier caseload increases the pressure to test infants earlier in order to ensure all infants are tested before being discharged. This was confirmed by the lower average screen age for Hospital B, where infants tested were, on average, only half the age (1.8 days; $1.0 \mathrm{SD}$ ) of those tested at Hospital A (3.1 days; 11.3 SD). Testing younger newborns, predisposed as they are to residual vernix in the ear canal and amniotic fluid in the middle ear, makes them less likely to 
pass the NHS than older infants (Gabbard, Northern \& Yoshinaga-Itano, 1999; Lupoli, Garcia \& Anastasio et al., 2013). Referral rates that are too high place an added burden on NHS programme resources and influence successful tracking and follow-up of referred infants (Yoshinaga-Itano, 2011).

\section{Follow-up rate}

NHS is the first step in the EHDI process, with follow-up testing of infants who fail NHS the key to successful EHDI for infants born with a hearing loss (Gaffney, Green \& Gaffney, 2010). Poor follow-up return rates for infants who have failed NHS remain a major challenge to existing programmes globally, with loss to follow-up of infants from hearing screening to diagnosis having been reported as $46.1 \%$ in the US (Olusanya et al., 2007; Hoffman, Muñoz, Bradham \& Nelson, 2011). In Nigeria, high referral rates and sub-par follow-up return rates were also reported for hospital-based (32.3\% and $16 \%$ respectively) and immunisation clinicbased (14.3\% and 48.1\% respectively) NHS programmes (Olusanya, 2009; Olusanya \& Akinyemi, 2009). In South Africa, NHS follow-up return rates that are in accordance with recommended minimum standards ( $\geq 70 \%$ ) are reportedly only reached by $28 \%$ of hospital based NHS programmes in the private health care sector (HPCSA, 2007; JCIH, 2007; Meyer, Swanepoel, le Roux \& van der Linde, 2012). This study found that follow-up return rates at both hospitals (56.1\% at Hospital $A ; 35.8 \%$ at Hospital $B$ ) were below recommended benchmarks (HPCSA, 2007; JCIH, 2007). The lack of timely follow-up contributes to delays in diagnosis of and intervention in hearing loss and has a detrimental impact on childhood development (Olusanya, 2009).

A lack of quality control and the inefficient tracking of caregivers following discharge, as well as a lack of support from other health care professionals in encouraging follow-up are possible factors contributing to poor follow-up rates in the South African private health care sector (Meyer, Swanepoel, le Roux \& van der Linde, 2012; Swanepoel, Ebrahim \& Joseph et al., 2007). Family issues, such as maternal education and literacy levels and socioeconomic status, EHDI programme funding and reimbursement of costs for audiological services to caregivers and service providers have been cited as possible barriers to followup (Hoffman, Muñoz, Bradham \& Nelson, 2011). Loss to follow-up could be addressed through the implementation of a comprehensive EHDI tracking and data management system.

In the South African public health care sector, follow-up return rates have also failed to meet proposed HPCSA benchmarks (HPCSA, 2007; Swanepoel, Hugo \& Louw, 2006; Meyer, Swanepoel, le Roux \& van der Linde, 2012). The length of time a programme has been in 
existence has been highlighted as an important contributor to poor follow-up rates, with more established programmes demonstrating higher follow-up return rates than more recent ones (Swanepoel, Hugo \& Louw, 2006). However, the current study did not find a statistical relationship between length of programme existence and follow-up return rates. Addressing parental and health care professional attitudes towards EHDI and the development of effective tracking and data management systems would add support to increasing follow-up return rates (Meyer, Swanepoel, le Roux \& van der Linde, 2012).

Satisfactory follow-up return rates have recently been reported in the Western Cape public health sector, where a dedicated screening coordinator has been employed to monitor the NHS programme through a system of telephone calls, home visits, training of personnel and visual reminders to track participants and to ensure follow-up compliance (Friderichs, Swanepoel \& Hall, 2012). This underscores the importance of dedicated personnel who can coordinate and manage a NHS programme where staff shortages have been cited as a major challenge to the successful tracking and follow-up of infants referred for further testing (Hoffman, Muñoz, Bradham \& Nelson, 2011).

In this study, it was found that screening programmes relied heavily on caregivers' compliance with the requirement to return for follow-up rescreening; there was little or no tracking by NHS programme staff. This failure to remind and encourage caregivers to comply with the recommended follow-up re-test may have affected follow-up rates adversely (Olusanya \& Akinyemi, 2009). Furthermore, follow-up rates could be improved by addressing caregivers' attitudes towards the necessity and reliability of NHS (Swanepoel, 2006; Swanepoel \& Almec, 2008).

While reported NHS coverage, referral and follow-up return rates across South Africa have been poor, to date the reasons for caregiver screen refusal and follow-up default have not been surveyed. The second part of this study investigated these reasons.

\subsubsection{NHS prospective surveys - Study II and Study III}

\section{Reasons for screen refusal and follow-up default}

In this study, the cost of NHS, caregiver knowledge of NHS and the level of support from health care professionals involved in infant care were most influential in caregivers' decisions to refuse NHS. Reasons for follow-up default given most frequently by caregivers were associated with their lack of awareness of the importance of follow-up. This was followed by reasons associated with a lack of systematic tracking of caregivers. In addition, 
the exclusion of NHS costs from hospitalisation birthing packages and from medical insurance as well as reasons associated with health care professionals' knowledge and team collaboration were also given as explanations for follow-up default.

Almost all caregivers (96\%) indicated that they would have agreed to NHS had the cost been included in the birthing package and/or covered by medical insurance. The cost of NHS is an important concern for caregivers and has an influence on screen refusal as well as on followup compliance. Maternal education and literacy levels as well as socio-economic status may contribute to follow-up default (Hoffman, Muñoz, Bradham \& Nelson, 2011) and screen refusal. These findings highlight the need for NHS to be made mandatory and part of national policy in both the private and the public health care sectors of South Africa. NHS costs should be included in hospitalisation birthing packages and covered by medical insurance, with centralised data management and quality control monitoring (Meyer, Swanepoel, le Roux \& van der Linde, 2012) to improve coverage and in order to ensure effective identification and subsequent management of permanent congenital and earlyonset infant hearing loss (Olusanya, 2009).

Caregiver awareness and education about NHS are vital for its successful implementation (Swanepoel \& Almec, 2008). Adverse cultural perspectives and the attitudes caregivers may have towards hearing loss and disabilities, as well the perception that hearing loss is not life threatening may influence parental involvement in EHDI, particularly affecting follow-up compliance (Olusanya, 2009). Parental awareness of EHDI can be improved through the timely introduction of appropriate information, preferably prior to the birth of the infant, such as in ante-natal clinics and at gynaecological consultations (DesGeorges, 2003). Parent education materials should be developed in multiple languages and made available to caregivers with newborns and with infants indentified with a hearing loss (Hoffman, Muñoz, Bradham \& Nelson, 2011). Pre-screening parental education should be complemented by extensive public awareness campaigns (Olusanya, 2009) in multiple languages (Hoffman, Muñoz, Bradham \& Nelson, 2011). Press releases and the development of EHDI websites (Hoffman, Muñoz, Bradham \& Nelson, 2011) may serve to encourage support from health care professionals and the wider community in South Africa (Olusanya, 2009). This recommendation is supported by the findings of a survey of NHS in the public health sector, where all caregivers (99\%) expressed a need for more information about EHDI (Swanepoel \& Almec, 2008). The study reported on in this dissertation revealed that caregivers who received written information were more likely to report that NHS was extremely important $(77.8 \%)$, that effective treatment was available for permanent congenital hearing loss (33.3\%) and that an audiologist was the professional responsible for NHS (44.4\%), than 
those caregivers who did not receive written information. The degree of understanding among caregivers of the importance of NHS is directly related to the level of caregiver participation (Moeller, White \& Shisler, 2006). Furthermore, high levels of caregiver involvement in intervention are associated with better language outcomes and more successful EHDI is achieved when families are actively involved (Moeller, 2000) Results of a survey investigating maternal views on EHDI in South Africa revealed that although at least one superstitious belief was held by more than half $(57 \%)$ of the participants, attitudes were overwhelmingly positive towards EHDI, with almost all mothers (99\%) expressing a desire to have their infant screened (Swanepoel \& Almec, 2008). This indicates a readiness for the widespread implementation of EHDI in South Africa in conjunction with increased caregiver knowledge of EHDI (Swanepoel \& Almec, 2008).

A follow-up rescreen appointment should be scheduled immediately (Hoffman, Muñoz, Bradham \& Nelson, 2011) to coincide with compulsory paediatric check-ups or hospital visits, in order to improve follow-up compliance. Findings from this study emphasise the importance of effective communication with the caregiver and the explanation of screen results and recommendations to this individual by the screener, accompanied by written information explaining NHS, the meaning of the screen results and the follow-up process (Hoffman, Muñoz, Bradham \& Nelson, 2011; Holte et al., 2012). A breakdown in clear communication of NHS results and the importance of follow-up interaction with the caregiver can have a negative effect on follow-up compliance (Mukari, Tan \& Abdullah, 2006; Olusanya, 2009). Although in the study reported on in this dissertation the screening results and recommendations were conveyed to caregivers both verbally and in writing, follow-up compliance might have been enhanced had a follow-up appointment been confirmed immediately after the screen refer. Effective screener-caregiver communication must be supported by the education of caregivers regarding NHS at pre-birth opportunities (Todd, 2006). The administration of efficient data management systems and tracking protocols (Mehl \& Thomson, 2002) by dedicated personnel through the use of telephone calls and visual reminders such as text messages and emails to inform caregivers of the need to follow up (Friderichs, Swanepoel \& Hall, 2012; Hoffman, Muñoz, Bradham \& Nelson, 2011) would facilitate and improve follow-up rescreen compliance. The lack of EHDI staff able to track and follow-up with caregivers of infants referred for retesting has been reported as a significant barrier to follow-up compliance (Hoffman, Muñoz, Bradham \& Nelson, 2011).

Data management systems should be governed by written policies and protocols, have NHS results reported within one week to ensure timely follow-up, and have a mechanism to report NHS findings and interventions to all team members (Hoffman, Muñoz, Bradham \& Nelson, 
2011). A national centralised web-based data tracking management system, possibly linked to other state data systems (e.g. National Health Laboratory Services) (Hoffman, Muñoz, Bradham \& Nelson, 2011), should be considered in order to accurately document NHS coverage and reduce follow-up default.

A number of caregivers (16\%) declined NHS because their paediatrician did not recommend it. A survey of NHS in the private health sector of South Africa revealed that limited awareness of the importance of NHS among health care professionals often undermines its successful implementation (Meyer \& Swanepoel, 2011). This emphasises the importance of team collaboration and increased awareness of NHS and continuing professional education amongst health care professionals involved in infant care (Olusanya, 2009). NHS results and follow-up recommendations should be conveyed to the primary care physician and other team members to facilitate prompt follow-up (Hoffman, Muñoz, Bradham \& Nelson, 2011). A team approach is essential in facilitating coverage and the follow-up process and in reducing delays in early intervention (Holte et al., 2012). Multiple parties who are involved in the infant's care and who encourage NHS and motivate caregivers to comply with follow-up retest recommendations will improve programme outcomes. Strengthening the medical community's knowledge and involvement, from screening to intervention, can better advocate and support NHS (Moeller, White \& Shisler, 2006).

\subsection{Clinical implications and recommendations}

South Africa is the strongest economic power in the sub-Saharan region and should therefore be leading this region in the advocacy and development of EHDI programmes (Swanepoel, Störbeck \& Friedland, 2009). NHS should be the standard of care for every infant to ensure optimal outcomes for those born with a hearing loss and for society at large (Meyer, Swanepoel, le Roux \& van der Linde, 2012; Swanepoel, Johl \& Pienaar, 2013; Swanepoel, Störbeck \& Friedland, 2009). Unfortunately, the majority of infants born in South Africa are not given the opportunity to have their hearing screened as a result of the limited NHS programmes in both the public and the private health care sectors (Meyer, Swanepoel, le Roux \& van der Linde, 2012; Swanepoel, Störbeck \& Friedland, 2009).

NHS programmes in the private health sector are scarce (Meyer, Swanepoel, le Roux \& van der Linde, 2012) and mostly implemented by the efforts of individual audiologists. NHS coverage and follow-up rates of these existing programmes have been reported as below the recommended benchmarks (HPCSA, 2007; JCIH, 2007; Meyer, Swanepoel, le Roux \& van der Linde, 2012; Swanepoel, Ebrahim \& Joseph et al., 2007), and the findings of this 
study support this trend. NHS must be seen as part of routine infant care, with the cost thereof covered by medical insurance, and included in state and hospital policy in order to facilitate the common practice of NHS and to curb screen-refusal by caregivers. In order to achieve this, parents, audiologists and other health care professionals involved in infant care (i.e. gynaecologists, paediatricians, nurses and midwives) must together promote the national implementation of mandatory NHS and the support of EHDI services in South Africa. This may act as a catalyst for the state to support NHS and EHDI and to initiate human resource development, public education and the introduction of a framework for the widespread implementation of NHS and EHDI programmes (Olusanya, 2012). The need to develop context specific strategies based on pilot studies conducted in South Africa is vital (Olusanya, 2012). Private and public health care sector partnerships must be developed in order to nationally roll-out NHS services.

As a result of the scarcity of audiologists in South Africa (Swanepoel, 2006), a collaborative team approach to NHS should be applied (Nelson, Houston, Hoffman \& Bradham, 2011) where all professionals involved in newborn infant care are educated in and engaged in NHS efforts. Many caregivers (64\%) who participated in this study were unaware of NHS and their knowledge of EHDI was poor, suggesting that educational material should be developed and issued to caregivers at pre-birthing opportunities where the NHS process and importance thereof is explained. Gynaecologists and personnel involved in ante-natal care are in the ideal position to inform caregivers before their infant is born of the recommendations and motivation supporting NHS and EHDI. This may curb the rate of caregiver screen refusal.

Screening personnel could include trained nurses and midwives who conduct NHS on every infant prior to hospital discharge. NHS practices could be overseen by a senior nurse or hospital maternity ward manager who could report on the programme characteristics (e.g. coverage, referral rate and demographics) and offer support to screening personnel. NHS programmes could be coordinated by an ear-care professional, such as an audiologist or ear, nose and throat specialist. Infants who fail NHS would be referred for diagnostic testing to the coordinating audiology practice or an audiologist who is part of the NHS team.

In order to encourage the follow-up process, NHS results should be communicated to an infant's paediatrician. This would support the multidisciplinary team approach and might encourage caregivers to follow up as the paediatrician can reinforce the importance thereof. NHS should furthermore be supported by ongoing education in NHS best practice for professionals involved in infant care. NHS team members should extend outreach efforts to 
professionals not currently engaged in the NHS and EHDI process (Hoffman, Muñoz, Bradham \& Nelson, 2011).

The importance of dedicated personnel who track infants recommended for follow-up should not be underestimated. When dedicated personnel are tasked with tracking caregivers, follow-up rates have been shown to be higher (Friderichs, Swanepoel \& Hall, 2012). A webbased tracking programme, possibly linked to an existing national data base where maternal and infant demographics as well as NHS results and follow-up recommendations are recorded, could facilitate the follow-up and tracking process.

\subsection{Critical evaluation}

The current study is the first of its kind to investigate the reasons for caregiver screen refusal and follow-up default in South Africa. It has provided insight into the characteristics of NHS in the private sector of South Africa and has added to the limited contextual research available. It has provided valuable information to guide the development of context specific NHS services in the private health sector of the Western Cape. It further advocates the need for the universal implementation of NHS and EHDI programmes in South Africa and for the support of existing NHS programmes in both the private and the public health sectors.

The findings of this study support evidence of the impact of demographics on screen coverage and rate of caregiver screen decline as well as the impact of infant age on referral rates. The findings highlight the importance of the communication of NHS screen results to the caregiver, and they provide support for the recommendation that extensive tracking frameworks with dedicated personnel be implemented (Friderichs, Swanepoel \& Hall, 2012) to improve follow-up rates.

The most frequently given reasons for screen refusal were cost related while those for follow-up default were related to caregiver knowledge of NHS. These findings add further support to the rallying of medical insurance and institutions to cover NHS costs and to campaigns to educate caregivers and professionals in the importance of NHS.

There were some limitations to this study. The investigations were conducted in the Western Cape only which may limit the application of these findings on a wider scale. Conducting this study in all provinces across South Africa would provide a more comprehensive indication of NHS programme characteristics and caregiver reasons for screen refusal and follow-up default in the private health sector. The broad time frame between the birth of the infant and the interviews with caregivers is a limitation of this study and may have influenced the 
accuracy of the responses. Sampling from one hospital only as well as the sample size of only 50 caregivers may also have limited the application of these findings. The collection of more comprehensive demographic data would allow a better understanding of the causes of caregiver screen refusal and follow-up default. This could help those running $\mathrm{NHS}$ programmes to focus their resources and efforts in service provision more efficiently on the most vulnerable populations (Gaffney, Green \& Gaffney, 2010). The lack of inclusion of infants admitted to the NICU limits the application of the findings to NHS programs conducted on infants admitted to well-baby nurseries and their caregivers only. Furthermore, response bias, which is most prevalent during research that requires participant self-report, may have influenced the validity of the caregiver responses during the telephonic surveys (Brink, van der Walt \& van Rensburg, 2012).

\subsection{Suggestions for future research}

This study has created a wide platform for further research. Similar studies should be conducted in all provinces across South Africa in order to obtain comprehensive information on the characteristics of existing NHS programmes in the private health sector. Caregivers' reasons for screen refusal and follow-up default should be investigated across South Africa in order to address these factors and concentrate resources on improving screen coverage and follow-up rates. A widespread implementation of this study might shed more light on the effect of demographics and socio-economic status on NHS programmes.

The tracking practices of existing NHS programmes could be explored in order to develop a standardised national protocol and data management system for the follow-up of infants referred for retesting. Pilot studies should be conducted to determine the effect of the inclusion of NHS costs in medical insurance and/or hospital packages as well as the effect of greater caregiver awareness of NHS and its importance on coverage and caregiver screen refusal rates. The knowledge and perceptions of professionals involved in infant care, including paediatricians and nurses, should also be further investigated in order to determine the level of support for NHS and EHDI by medical professionals in South Africa and to develop strategies to address any limitations in this regard.

\subsection{Conclusion}

There are many challenges facing the successful nationwide roll-out of NHS and EHDI services in South Africa, including inadequate NHS coverage, refusal of NHS by caregivers and high rates of follow-up default. Coverage and follow-up rates of the NHS programmes 
investigated in this study did not meet the recommended benchmarks (HPCSA, 2007; JCIH, 2007). This study revealed that issues of cost were the most common factors related to screen refusal. Caregivers' lack of knowledge of screen outcome and follow-up recommendations were most commonly related to follow-up default. The most pressing challenge to service delivery is the failure to mandate both the inclusion of NHS in hospital policy and the coverage of its costs by medical insurance. Limited understanding of the importance of EHDI among caregivers and health care professionals contributes to the undermining of service delivery. This study revealed that if caregivers received written information about NHS they were more likely to have a positive attitude towards the programme and to develop a more accurate understanding of NHS. Follow-up return rates reflected in this study might have been increased had a centralised data management and quality control tracking system been in place, preferably staffed by dedicated personnel.

Until these shortcomings are addressed and NHS becomes mandatory in South Africa, many infants with hearing loss will continue to go undetected, and those who are screened may receive inadequate follow-up services. 


\section{REFERENCES}

Biermann J. (2006). South Africa's health care under threat. Free Market Foundation and International Policy Network 2006; ISBN: 1-874930-71-6. Retrieved from www.healthpolicyunit.org/downloads/Health_Care_under_Threat.pdf.

Brink, H., van der Walt, C. \& van Rensburg, G. (2012). Fundamentals of research methodology for healthcare professionals (3rd ed.). Juta \& Company Ltd.

Ching, T.Y.C., Day, J., Seeto, M., Dillon, H., Marnane, V. \& Street, L. (2013). Predicting 3year outcomes of early-identified children with hearing impairment. $B-E N T, 21,99-106$.

City of Cape Town, city statistics and population census, 2011 census. Retrieved from http://www.capetown.gov.za/en/stats/Pages/Census2011aspx.

DesGeorges, J. (2003). Family perceptions of early hearing, detection, and intervention systems: Listening to and learning from families. Mental Retardation and Developmental Disabilities Research Reviews, 9, 89-93.

De Vos, A.S., Strydom, H., Fouché, C.B. \& Delport, L.S.L. (2005). Research at grass roots. For social sciences and human service professionals (3rd ed.). Pretoria: Van Schaik.

Fulcher, A., Purcell, A.A., Baker, E. \& Munro, N. (2012). Listen-up: Children with early identified hearing loss achieve age-appropriate speech/language outcomes by 3 years-ofage. International Journal of Pediatric Otorhinolaryngology, 76, 1785-1794.

Friderichs, N., Swanepoel, D. \& Hall, J.W. (2012). Efficacy of a community-based infant screening program utilizing existing clinic personnel in Western Cape, South Africa. International Journal of Pediatric Otorhinolaryngology, 76, 552-559.

Gabbard, S.A., Northern, J.L. \& Yoshinaga-Itano, C. (1999). Hearing screening in newborns under 24 hours of age. Seminars in Hearing, 4 (20), 291-307.

Gaffney, M., Eichwald, J., Grosse, S.D. \& Mason, C.A. (2010). Identifying infants with hearing loss - United States, 1999-2007. Centers for Disease Control and Prevention Morbidity and Mortality Weekly Report, 59 (8), 220-223. Retrieved from www.cdc.gov/mmwr/preview/mmwrhtml/mm5908a2.htm?s_cid=mm5908a2_e. 
Gaffney, M., Green, D.R. \& Gaffney, C. (2010). Newborn hearing screening and follow-up: are children receiving recommended services? Public Health Reports, 125, 199-207.

Goedert, M.H., Moeller, M.P. \& White, K.R. (2011). Midwives' knowledge, attitudes and practices related to newborn hearing screening. Journal of Midwifery and Women's Health, 56(2), 147-153.

Harrison, M., Roush, J. \& Wallace, J. (2003). Trends in age of identification and intervention in infants with hearing loss. Ear and Hearing, 24(1), 89-95.

Hicks, C. (2004). Research methods for clinical therapists. Applied project design and analysis (4th ed.). Edinburgh; New York: Churchill Livingstone.

Health Professions Council of South Africa. (2007). Professional board for speech, language and hearing profession: Early hearing detection and intervention programmes in South Africa, position statement year 2007, 1-42. Retrieved from http://www.hpcsa.co.za/downloads/speech_education/early_hearing_detection_statement.pd f.

Hoffman, J., Muñoz, K.F., Bradham, T.S. \& Nelson, L. (2011). Loss to follow-up: Issues and recommendations. The Volta Review, 111(2), 165-180.

Holte, L., Walker, E., Oleson, J., Spratford, M., Moeller, M.P., Roush, P, Ou, H. \& Tomblin, J.B. (2012). Factors influencing follow-up to newborn hearing screening for infants who are hard of hearing. American Journal of Audiology, 21, 163-174.

Joint Committee on Infant Hearing (JCIH). (2007). Year 2007 position statement: principles and guidelines for early hearing detection and intervention programs. Pediatrics 120(4), 899-921.

Kemper, A. R. (2011). Translating best evidence into best care. The Journal of Pediatrics, 158(5), 859. Retrieved from http://download.journals.elsevierhealth.com/pdfs/journals/00223476/PIIS0022347611002666.pdf.

Leedy, P.D. \& Ormrod, J.E. (2005). Practical research: Planning and design. (8th ed.). USA: Merril Publishing Company. 
Lupoli, L.M., Garcia, L., Anastasio, A.R.T. \& Fontana, A.C. (2013). Time after birth in relation to failure rate in newborn hearing screening. International Journal of Pediatric Otorhinolaryngology, 77(6). Retrieved from http://dx.doi.org/10.1016/j.ijporl.2013.03.010.

Maxwell, D.L., \& Satake, E. (1997). Research and statistical methods in communication disorders. Maryland: Williams \& Wilkins.

Mehl, A.L. \& Thomson, V. (1998). Newborn hearing screening: The great omission. Pediatrics, 101(e4). Retrieved from http://pediatrics.aappublications.org/content/101/1/e4.full.html.

Mehl, A.L. \& Thomson, V. (2002). The Colorado newborn hearing screening project, $1992-$ 1999: On the threshold of effective population-based universal newborn hearing screening. Pediatrics, 109(e7). Retrieved from http://pediatrics.aappublications.org/content/109/1/e7.full.html.

Meinzen-Derr, J., Wiley, S. \& Choo, D.I. (2011). Impact of early intervention on expressive and receptive language development among young children with permanent hearing loss. American Annals of the Deaf, 155(5), 580-591.

Meyer, M.E. \& Swanepoel, D.W. (2011). Newborn hearing screening in the private health sector - a national survey. South African Medical Journal, 101(9), 665-667.

Meyer, M.E., Swanepoel, D., le Roux, T. \& Van der Linde, M. (2012). Early detection of infant hearing loss in the private health care sector of South Africa. International Journal of Pediatric Otorhinolaryngology, 76, 698-703.

Moeller, M.P. (2000). Early intervention and language development in children who are deaf and hard of hearing. International Journal of Pediatric Otorhinolaryngology, 103(e43). Retrieved from http://pediatrics.aappublications.org/content/106/3/e43.full.html.

Moeller, M.P., White, K.R. \& Shisler, L. (2006). Primary care physicians' knowledge, attitudes and practices related to newborn hearing screening. Pediatrics, 118(4), 1357-1370.

Morton, C.C. \& Nance, W.E. (2006). Newborn hearing screening - a silent revolution. The New England Journal of Medicine, 354(20), 2151-2164. 
Mouton, J. (2001). How to succeed in your master's and doctoral studies: A South African guide and resource book. Pretoria: Van Schaik.

Mrug, S. (2010). Survey. Encyclopedia of research design. Retrieved from http://0www.sage-ereference.com.innopac.up.ac.za/researchdesign/Article_n449.html.

Mukari, S.Z., Tan, K.Y. \& Abdullah, A. (2006). A pilot project on hospital-based universalnewborn hearing screening: Lessons learned. International Journal of Pediatric Otorhinolaryngology, 70(5), 843-851.

Nelson, H.D., Bougatsos, C. \& Nygren, P. (2008). Universal newborn hearing screening: systematic review to update the 2001 US preventive services task force recommendation. Pediatrics 122, e266-e276. doi: 10.1542/peds.2007-1422.

Nelson, L., Bradham, T.S. \& Houston, K.T. (2011) The EHDI and early intervention connection. The Volta Review, 111(2), 133-149.

Olusanya, B.O. (2007). Addressing the global neglect of childhood hearing impairment in developing countries. PLoS medical, 4(4), e72, 0626-0630.

doi:10.1371/journal.pmed.0040074.

Olusanya, B.O. (2008). Priorities for early hearing detection and intervention in sub-Saharan Africa. International Journal of Audiology, 47(Suppl 1), S3-S13. doi: 10.1080/14992020802287143.

Olusanya, B.O. (2009). Follow-up default in a hospital-based universal newborn hearing screening programme in a low income country. Child: Health, Care and Development, 35(2), 190-198. doi:10.1111/j.1365-2214.2008.00923.x.

Olusanya, B.O. (2012). Neonatal hearing screening and intervention in a resource-limited setting: An overview. Archives of Disease in Childhood, 97, 654-659.

Olusanya, B.O. \& Akinyemi, O.O. (2009). Community-based infant hearing screening in a developing country: Parental uptake of follow-up services. BMC Public Health, 9(66). Retrieved from http://www.biomedcentral.com/1471-2458/9/66. 
Olusanya, B.O., McPherson, B., Swanepoel, D., Shrivastav, R. \& Chapchap, M. (2006). Globalization of infant hearing screening: the next challenge before $\mathrm{JCIH}$ ? Journal of the American Academy of Audiology, 17, 293-296.

Olusanya, B.O., Luxon, L.M. \& Wirz, S.L. (2004a). Benefits and challenges of newborn hearing screening for developing countries. International Journal of Pediatric Otorhinolaryngology, 68(3), 287-305.

Olusanya, B.O., Luxon, L.M. \& Wirz, S.L. (2004b). Infant hearing screening: A route to informed choice. Archives of Disease in Childhood, 89, 1039-1040.

Olusanya, B.O., Wirz, S.L. \& Luxon, L.M. (2008). Hospital-based universal newborn hearing screening for early detection of permanent congenital hearing loss in Lagos, Nigeria, International Journal of Pediatric Otorhinolaryngology, 72, 991-1001.

Olusanya, B.O. \& Newton, V.E. (2007). Global burden of childhood hearing impairment and disease control priorities for developing countries. Lancet, 369, 1314-1317.

Olusanya, B.O., Swanepoel, D., Chapchap, M.J., Castillo, S., Habib, H., Mukari, S.Z., Martinez, N.V., Lin, H.-C. \& McPherson, B. (2007). Progress towards early detection services for infants with hearing loss in developing countries. BMC Health Services Research, 7, 14.

Pallarito, K. (2012). Quality improvement efforts target gaps in newborn hearing screening programs. The Hearing Journal, 65(9), 18-22.

Pimperton, H. \& Kennedy, C.R. (2012). The impact of early identification of permanent childhood hearing impairment on speech and language outcomes. Archives of Disease in Childhood, 97, 648-653.

Statistics South Africa, Census 2001, Community profile databases. Retrieved from http://census.adrianfrith.com/.

Struwig, F.W. \& Stead, G.B. (2001). Planning, designing and reporting research. Cape Town: Pearson Education South Africa. 
Swanepoel, D. (2006). Audiology in South Africa. International Journal of Audiology, 45(5), 262-266.

Swanepoel, D. \& Almec, N. (2008). Maternal views on infant hearing loss and early intervention in a South African community. International Journal of Audiology, 47(Suppl. 1), S47-S48.

Swanepoel, D., Delport, S. \& Swart, J.G. (2004). Universal newborn hearing screening in South Africa: A first world dream? South African Medical Journal, 94(8), 634635.

Swanepoel, D., Ebrahim, S., Joseph, A. \& Friedland, P.L. (2007). Newborn hearing screening in a South African private health care hospital. International Journal of Pediatric Otorhinolaryngology, 71, 881-887. doi: 10.1016/j.jporl.2007.02.009.

Swanepoel, D., Hugo, R. \& Louw, B. (2006). Infant hearing screening at immunization clinics in South Africa. International Journal of Pediatric Otorhinolaryngology, 70(7), 1241-1249.

Swanepoel, D., Johl, L. \& Pienaar, D. (2013). Childhood hearing loss and risk profile in a South African population. International Journal of Pediatric Otorhinolaryngology, 77(3), 394398.

Swanepoel, D. \& Störbeck, C. (2008). EHDI Africa: advocating for infants with hearing loss in Africa. International Journal of Audiology, 47(Suppl. 1), S1-S2.

Swanepoel, D., Störbeck, C. \& Friedland, P. (2009). Early hearing detection and intervention services in South Africa. International Journal of Pediatric Otorhinolaryngology, 73(6), 783786.

Smith, R.J.H., Bale, J.F. \& White, K.R. (2005). Sensorineural hearing loss in children. Lancet, 365, 879-890.

Tann, J., Wilson, W.J., Bradley, A.P. \& Wanless, G. (2009). Progress towards universal neonatal hearing screening: A world review. The Australian and New Zealand Journal of Audiology, 31(1), 3-14. 
Theunissen, M. \& Swanepoel, D. (2008). Early hearing detection and intervention services in the public health sector in South Africa. International Journal of Audiology, 47(Suppl. 1), S23-S29. doi: 10.10801/14992020802294032.

Todd, N.W. (2006). Universal newborn hearing screening follow-up in two Georgia populations: newborn, mother and system correlates. International Journal of Audiology, 70(5), 807-815.

Van der Spuy, T. \& Pottas, L. (2008). Infant hearing loss in South Africa: Age of intervention and parental needs for support. International Journal of Audiology, 47(Suppl. 1), S30-S35.

Wagner, W., Heppelmann, G., Vonthein, R. \& Zenner, H.P. (2008). Test-retest repeatability of distortion product otoacoustic emissions. Ear \& Hearing, 2(3), 378-391.

White, K.R. \& Blaiser, K.M. (2011). Strategic planning to improve EHDI programs. The Volta Review, 111(2), 83-108.

World Health Organization. (2012). WHO global estimates on prevalence of hearing loss. Mortality and burden of diseases and prevention of blindness and deafness. Geneva, Switzerland: WHO Press, 120-121. Retrieved from http://www.who.int/pbd/deafness/WHO_GE_HL.pdf.

Yoshinaga-Itano, C. (2003). Universal newborn hearing screening programs and developmental outcomes. Audiological Medicine, 1, 199-206.

Yoshinaga-Itano, C. (2004). Levels of evidence: Universal newborn hearing screening (UNHS) and early hearing detection and intervention systems (EHDI). Journal of Communication Disorders, 37(5), 451-465.

Yoshinaga-Itano, C. (2011). Achieving optimal outcomes from EHDI. The AHSA Leader, 1417.

Yoshinaga-Itano, C. \& Apuzzo, M. L. (1998). The development of deaf and hard of hearing children identified early through the high-risk register. American Annals of the Deaf, 143(5), 416-424. 
Yoshinaga-Itano, C., Coulter, D. \& Thomson, V. (2001). Developmental outcomes of children with hearing loss born in Colorado hospitals with and without newborn hearing screening programs. Seminars in Neonatology, 6, 521-529.

Yoshinaga-Itano, C. \& Gravel, J.S. (2001). The evidence for universal newborn hearing screening. American Journal of Audiology, 10(2), 62-64.

Yoshinaga-Itano, C., Sedey, A., Coulter, D. \& Mehl, A. (1998). Language of early and lateridentified children with hearing loss. American Academy of Pediatrics, 102(5), 1161-1171.

Yoshinaga-Itano, C. \& Thomson, V. (2008). The work of the Village: Creating a new world for children with hearing loss and their families. International Journal of Audiology, 47(Suppl. 1), S14-S22. 
6. APPENDICES 
Appendix A: Letter of consent: Private practice owner 
UNIVERSITEIT VAN PRETORIA

UNIVERSITY OF PRETORIA

YUNIBESITHI YA PRETORIA

Department of Communication Pathology

18 August 2010

Ms Liezel Kotzé

13 Fairway Street

Bellville

Cape Town

7530

\section{Dear Ms Kotzé}

\section{RE: RECORD REVIEW OF AN INFANT HEARING SCREENING PROGRAMME FOR RESEARCH PURPOSES}

I am currently doing my Masters degree with the University of Pretoria and I am eager to conduct a research study entitled: Infant hearing screening in private practice in the Western Cape: Programme efficacy and reasons for screen refusal and follow-up defaults. I would thus like to obtain permission to conduct research on the records of the Infant hearing screening programme conducted by the private practices owned by you, as well as to conduct a telephonic survey on fifty randomly selected parents/caregivers enrolled in the Infant screening programme. The study does not aim to audit the Infant hearing screening programme, it aims to:

- To describe the screening characteristics of the programme

- To describe the follow-up characteristics of the programme

- To describe the prevalence and nature of detected hearing loss

- To describe the reasons for test refusal

- To describe the reasons for follow-up default

All research conducted will not interfere with service delivery. The study will entail analysing the data of the Infant hearing screening programme already collected over the last three to four years. A sub-component of the study will involve collecting data through the use of a telephonic survey of twenty-five randomly selected parents/caregivers who declined hearing screening for their infants and twenty-five parents/caregivers who failed to bring their infants for follow-up hearing screening and their reasons for doing so. Informed consent to participate in this telephonic survey will be obtained verbally from these subjects informing them of the purpose and nature of the study and that all responses will be kept strictly confidential. Parent/caregivers will be verbally informed of the study during the initial telephonic contact and prior to any commencement of the survey or survey questions.

There are no financial obligations related to participation in the research to you or the participants. There are also no medical risks associated with the research.

Before any data collection commences, ethical clearance will be obtained from The University of Pretoria. You will be informed when this ethical clearance has been obtained and when data collection will commence. Participation is strictly voluntary and should you or the participants decide to withdraw your consent at any time there will be no negative consequences. 
Information regarding the research and the results will be provided upon your request at any time during the research process. All information of participants and data will be treated with the strictest confidentiality. A copy of the raw data will be stored in electronic format at The University of Pretoria for a period of 15 years for archiving and research purposes. No identifying information of any participants will be included in the data to be stored as each participant will be allocated a code. The findings of the study will be made available as a master's degree thesis and may be presented at scientific conferences and published in subject journals. All participants will have access to the data obtained in this project upon request.

I would therefore like to request access to the Infant hearing screening programme records of infants participating in your established hearing screening programmes at Netcare Kuils River and Netcare Blaauwberg. Your identity, the names of the specified private practices and the identity of the infants and parents/caregivers enrolled in the study will not be revealed and all information is to be treated in the strictest of confidence.

Please do not hesitate to contact me should you require any further information (Tel: 021946 3620; email: luciai@webmail.co.za).

Sincerely,

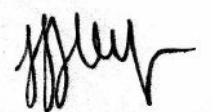

Ms Lucia Scheepers

Postgraduate student / researcher

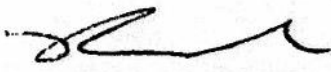

Prof De Wet Swanepoel

Research supervisor

Dr Maggi Soer
ACTING HEAD: Dopt of Communication Pathology

Communication Pathology Bldg R3-5 University of Pretoria

PRETORIA 0002

Republic of South Africa 
Attention: Ms. Scheepers

\title{
RE: PERMISSION TO ACCESS INFANT HEARING SCREENING PROGRAMME RECORDS FOR RESEARCH PURPOSES
}

I hereby declare that I have read and understood the attached letter of informed consent. I grant Ms. Scheepers direct access to the Infant hearing screening records of infants and parents/caregivers participating in the Infant hearing screening programmes of Liezel Kotzé Inc. at Netcare Kuilsriver and Netcare Blaauwberg. I understand that the results of the study will be published and that the raw data will be kept at the University of Pretoria for 15 years and may be made available for other research purposes. The identity of the infants and the parents/caregivers as well as the owner of the private practices specified will be kept confidential at all times. No names will be documented as each participant will be assigned a code.

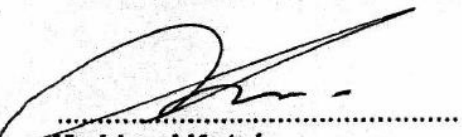

Ms Liezel Kotzé

Proprietor: Liezel Kotzé Inc. (Netcare Kuils River and Netcare Blaauwberg)

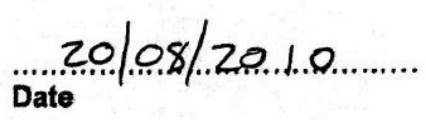

\author{
LIEZEL KOTZE INC. $12005 / 005519 / 21$ \\ AUDIOLOGIST \& SPEECH THERAPIST \\ 13 FAIRWAY STREET \\ BELLVILLE, 7530 \\ TEL: (21) $946-3620$ FAX: (021) $946-3626$ \\ CELL: 0833281326
}


Appendix B: Ethical clearance letter 
UNIVERSITEIT VAN PRETORIA

UNIVERSITY OF PRETORIA

YUNIBESITHI YA PRETORIA

Faculty of Humanities Office of the Deputy Dean

3 November 2010

Dear Prof Swanepoel,

Project:

Infant hearing screening in private practice in the Western Cape: programme efficacy and reason for screening refusal and follow-up default

Researcher:

LJ Scheepers

Supervisor:

Department:

Prof DCD Swanepoel

Reference number:

Communication Pathology

23051592

I am pleased to be able to tell you that the above application was approved (with comment) by the Postgraduate Committee on 12 October 2010 and by the Research Ethics Committee on 2 November 2010. Data collection may therefore commence.

Please note that this approval is based on the assumption that the research will be carried out along the lines laid out in the proposal. Should the actual research depart significantly from the proposed research, it will be necessary to apply for a new research approval and ethical clearance.

The Committee requests you to convey this approval to the researcher.

We wish you success with the project

Sincerely

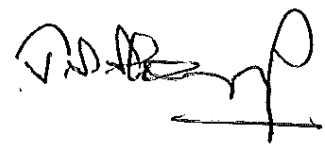

Prof John Sharp

Chair: Postgraduate Committee \&

Research Ethics Committee

Faculty of Humanities

UNIVERSITY OF PRETORIA

e-mail: john.sharp@up.ac.za 
Appendix C: Retrospective record review (Study I) data collection form 


\section{DATA COLLECTION FORM}

WHY PARENTS REFUSE NEWBORN HEARING SCREENING AND DEFAULT ON FOLLOW-UP RESCREENING - A SOUTH AFRICAN PERSPECTIVE

Private practice

Year

SECTION A: DEMOGRAPHIC INFORMATION

\begin{tabular}{|l|l|l|l|l|}
\hline Participant code & & & & \\
\hline Date of birth & & & & \\
\hline Sex & & & & \\
\hline Birth weight & & & & \\
\hline Apgar 1 min & & & & \\
\hline Apgar 5 min & & & & \\
\hline Pregnancy duration & & & & \\
\hline Birth type & & & & \\
\hline Maternal age & & & & \\
\hline $\begin{array}{l}\text { Medical } \\
\text { (specify) }\end{array}$ & & & & \\
\hline NICU & & & & \\
\hline Risk factor 1 & & & & \\
\hline Risk factor 2 & & & \\
\hline Risk factor 3 & & & \\
\hline Risk factor 4 & & & \\
\hline
\end{tabular}

\section{SECTION B: INITIAL TEST}

\begin{tabular}{|l|l|l|l|l|}
\hline Date of service & & & & \\
\hline Gestational age & & & & \\
\hline Decline test & & & & \\
\hline Location & & & & \\
\hline $\begin{array}{l}\text { OAE result: Right } \\
\text { ear }\end{array}$ & & & & \\
\hline OAE result :Left ear & & & & \\
\hline 6 week follow-up & & & \\
\hline
\end{tabular}

\section{SECTION C: FOLLOW-UP TEST}

\begin{tabular}{|l|l|l|l|l|}
\hline Return for follow-up & & & & \\
\hline Date of service & & & & \\
\hline Gestational age & & & & \\
\hline $\begin{array}{l}\text { OAE result: Right } \\
\text { ear }\end{array}$ & & & & \\
\hline OAE result: Left ear & & & & \\
\hline AABR & & & \\
\hline
\end{tabular}


SECTION D: AUTOMATED ABR SCREENING

\begin{tabular}{|l|l|l|l|l|}
\hline Return for AABR & & & & \\
\hline Date of service & & & & \\
\hline Gestational age & & & & \\
\hline $\begin{array}{l}\text { AABR result: Right } \\
\text { ear }\end{array}$ & & & & \\
\hline AABR result: Left & & & \\
ear & & & & \\
\hline Diagnostic test & & & \\
\hline
\end{tabular}

\section{SECTION E: DIAGNOSTIC TEST}

\begin{tabular}{|l|l|l|l|l|}
\hline $\begin{array}{l}\text { Return for } \\
\text { diagnostic }\end{array}$ & & & \\
\hline Date of service & & & & \\
\hline Gestational age & & & & \\
\hline $\begin{array}{l}\text { Diagnostic result: } \\
\text { Right ear result: }\end{array}$ & & & & \\
\hline $\begin{array}{l}\text { Diagnostic ear } \\
\text { Left ear }\end{array}$ & & & \\
\hline
\end{tabular}

\section{SECTION F: 1 YEAR FOLLOW-UP TEST}

\begin{tabular}{|l|l|l|l|l|}
\hline Return for follow-up & & & & \\
\hline Date of service & & & & \\
\hline Gestational age & & & & \\
\hline $\begin{array}{l}\text { OAE result: Right } \\
\text { ear }\end{array}$ & & & & \\
\hline OAE result: Left ear & & & \\
\hline
\end{tabular}




\begin{tabular}{|c|c|}
\hline KEY & \\
\hline 1 & Private practice $B B$ \\
\hline 2 & Private practice $K R$ \\
\hline 3 & Male \\
\hline 4 & Female \\
\hline 5 & Normal vaginal delivery (NVD) \\
\hline 6 & Caesarian section \\
\hline 7 & NVD with vacuum \\
\hline 8 & NVD with instruments \\
\hline 9 & Discovery \\
\hline 10 & GEMS \\
\hline 11 & Prosano \\
\hline 12 & Transmed \\
\hline 13 & Yes \\
\hline 14 & No \\
\hline 15 & Family history hearing loss \\
\hline 16 & Family history syndrome \\
\hline 17 & Cytomegalovirus \\
\hline 18 & Toxoplasmosis \\
\hline 19 & German measles \\
\hline 20 & Herpes simplex \\
\hline 21 & Syphilis \\
\hline 22 & HIVIAIDS \\
\hline 23 & Diabetes during gestation \\
\hline 24 & Medication during gestation \\
\hline 25 & Low birth weight \\
\hline 26 & Ototoxic medication \\
\hline 27 & Hyperbilirubinemia \\
\hline 28 & Mechanical ventilation \\
\hline 29 & Craniofacial anomaly \\
\hline 30 & Pass \\
\hline 31 & Fail \\
\hline 32 & Other (specify) \\
\hline 33 & Other (specify) \\
\hline
\end{tabular}


Appendix D: Telephonic Survey: Reasons for screen refusal (Study II) 
TELEPHONIC SURVEY: WHY PARENTS REFUSE NEWBORN HEARING SCREENING AND DEFAULT ON FOLLOW-UP RESCREENING - A SOUTH AFRICAN PERSPECTIVE REASONS FOR SCREEN REFUSAL

\begin{tabular}{|l|l|}
\hline For official use \\
\hline Participant code & \\
\hline Private practice & \\
\hline Date of service & \\
\hline
\end{tabular}

\section{SECTION A: DEMOGRAPHIC INFORMATION}

\begin{tabular}{|l|l|l|}
\hline Variable & & For official use \\
\hline Date of birth & & $V 1$ \\
\hline Gender & & V2 \\
\hline Pregnancy duration & & $V 3$ \\
\hline Birth type & & $V 4$ \\
\hline Birth weight & & $V 6$ \\
\hline APGAR: 1 min & & $V 7$ \\
\hline APGAR: 5 min & & $V 8$ \\
\hline Maternal Age & & $V 9$ \\
\hline Medical Aid & & $V 10$ \\
\hline Risk Factor 1 & & $V 11$ \\
\hline Risk Factor 2 & & $V 12$ \\
\hline Risk Factor 3 & & $V 13$ \\
\hline Risk Factor 4 & & \\
\hline
\end{tabular}

\section{SECTION B: CAREGIVER KNOWLEDGE OF NEWBORN HEARING SCREENING (NHS)}

1. Would you be willing to participate in this survey?

\begin{tabular}{|l|l|l|}
\hline Yes & & $V 14$ \\
\hline No & & $V 15$ \\
\hline If No, then please specify reason & & $V 16$ \\
\hline
\end{tabular}

2. Did you receive information regarding NHS?

\begin{tabular}{|l|l|l|}
\hline Yes & & $V 17$ \\
\hline No & & V18 \\
\hline Unsure & & $V 19$ \\
\hline
\end{tabular}

3. If yes, where did you receive this information from?

\begin{tabular}{|l|l|l|}
\hline Storks nest/ante-natal classes & & V20 \\
\hline Paediatrician & & V21 \\
\hline Audiologist & & V22
\end{tabular}




\begin{tabular}{|l|l|l|}
\hline Hospital nursing staff & & V23 \\
\hline Previous birth/child born & & V24 \\
\hline Other (specify) & & V25 \\
\hline
\end{tabular}

4. Did an Audiologist approach you (in person or telephonically following discharge) to inform you of the hearing screening programme in an in-patient and an out-patient basis to offer to screen your child's hearing?

\begin{tabular}{|l|l|l|}
\hline Yes & & V26 \\
\hline No & & V27 \\
\hline Unsure & & V28 \\
\hline
\end{tabular}

5. Did you receive an information pamphlet explaining the hearing screening programme and the importance thereof and stating the audiology practice contact details?

\begin{tabular}{|l|l|l|}
\hline Yes & & V29 \\
\hline No & & V30 \\
\hline Unsure & & V31 \\
\hline
\end{tabular}

6. Are you aware of the negative impact hearing loss can have on a child's development?

\begin{tabular}{|l|l|l|}
\hline Yes & & V32 \\
\hline No & & V33 \\
\hline Unsure & & V34 \\
\hline
\end{tabular}

\section{SECTION C: INITIAL TEST}

7. If you are aware of the recommended hearing screening and NHS was explained to you, what is the reason you refused hearing screening. You may select more than one answer.

\begin{tabular}{|l|l|l|}
\hline $\begin{array}{l}\text { My medical aid does not pay for } \\
\text { hearing screening }\end{array}$ & V35 \\
\hline $\begin{array}{l}\text { NHS was not included in the } \\
\text { hospitalisation package }\end{array}$ & V36 \\
\hline $\begin{array}{l}\text { I was not reminded to bring my } \\
\text { child for NHS post-discharge }\end{array}$ & V37 \\
\hline I feel it is not necessary & V38 \\
\hline $\begin{array}{l}\text { I was unaware of the practice } \\
\text { contact details maediatrician did not }\end{array}$ & V39 \\
\hline $\begin{array}{l}\text { The prest mended the test with my } \\
\text { recommensult to const }\end{array}$ & V40 \\
\hline $\begin{array}{l}\text { spouse first } \\
\text { Other }\end{array}$ & V41 \\
\hline
\end{tabular}


8. Would you have agreed to NHS if it was included in the hospitalization package?

\begin{tabular}{|l|l|l|}
\hline Yes & & V43 \\
\hline No & & V44 \\
\hline Unsure & & V45 \\
\hline
\end{tabular}

9. Would you have agreed to NHS if it was covered by medical aid?

\begin{tabular}{|l|l|l|}
\hline Yes & & V46 \\
\hline No & & V47 \\
\hline Unsure & & V48 \\
\hline
\end{tabular}

\section{SECTION D: FOLLOW-UP TEST}

10. Are you aware, that due to the nature of the equipment used for hearing screening, a follow-up at 1 year of age is recommended to monitor hearing?

\begin{tabular}{|l|l|l|}
\hline Yes & & V49 \\
\hline No & & V50 \\
\hline Unsure & & V51 \\
\hline
\end{tabular}

11. Would you be interested in bringing your child for hearing screening?

\begin{tabular}{|l|l|l|}
\hline Yes & & V52 \\
\hline No & & V53 \\
\hline Unsure & & V54 \\
\hline
\end{tabular}

12. If not, why not? You may select more than one answer.

\begin{tabular}{|l|l|l|}
\hline $\begin{array}{l}\text { The medical aid does not pay, I } \\
\text { am unwilling to pay myself }\end{array}$ & V55 \\
\hline I feel it is not necessary & & V56 \\
\hline $\begin{array}{l}\text { The paediatrician did not } \\
\text { recommended the test }\end{array}$ & V57 \\
\hline Other & & V58 \\
\hline
\end{tabular}

13. Is there any comment you would like to make?

Your participation is appreciated, thank you! 
Appendix E: Telephonic Survey: Reasons for follow-up default (Study III) 
TELEPHONIC SURVEY: WHY PARENTS REFUSE NEWBORN HEARING SCREENING AND DEFAULT ON FOLLOW-UP RESCREENING - A SOUTH AFRICAN PERSPECTIVE REASONS FOR FOLLOW-UP DEFAULT

\begin{tabular}{|l|l|}
\hline For official use \\
\hline Participant code & \\
\hline Private practice & \\
\hline Date of service & \\
\hline Location of initial test & \\
\hline
\end{tabular}

\section{SECTION A: DEMOGRAPHIC INFORMATION}

\begin{tabular}{|l|l|l|}
\hline Variable & & For official use \\
\hline Date of birth & & $V 1$ \\
\hline Gender & & $V 2$ \\
\hline Pregnancy duration & & $V 3$ \\
\hline Birth type & & $V 4$ \\
\hline Birth weight & & $V 5$ \\
\hline APGAR: 1 min & & $V 6$ \\
\hline APGAR: 5 min & & $V 7$ \\
\hline Maternal Age & & $V 8$ \\
\hline Medical Aid & & $V 9$ \\
\hline Risk Factor 1 & & $V 10$ \\
\hline Risk Factor 2 & & $V 11$ \\
\hline Risk Factor 3 & & $V 12$ \\
\hline Risk Factor 4 & & $V 13$ \\
\hline
\end{tabular}

\begin{tabular}{|l|l|l|}
\hline Ear & OAE result & For official use \\
\hline Right & & V14 \\
\hline Left & & V15 \\
\hline
\end{tabular}

\section{SECTION B: CAREGIVER KNOWLEDGE OF NEWBORN HEARING SCREENING (NHS)}

13. Would you be willing to participate in this survey?

\begin{tabular}{|l|l|l|}
\hline Yes & & $V 16$ \\
\hline No & & $V 17$ \\
\hline $\begin{array}{l}\text { If No, then please specify } \\
\text { reason }\end{array}$ & V18 \\
\hline
\end{tabular}

14. Your child's hearing was screened with your informed consent, where did you receive information regarding NHS?

\begin{tabular}{|l|l|l|}
\hline $\begin{array}{l}\text { Storks nest/ante-natal } \\
\text { classes }\end{array}$ & V19 \\
\hline Peadiatrician & & V20 \\
\hline
\end{tabular}




\begin{tabular}{|l|l|l|}
\hline Audiologist & & V21 \\
\hline Hospital nursing staff & & V22 \\
\hline Previous birth/child born & & V23 \\
\hline Other (specify) & & V24 \\
\hline
\end{tabular}

15. Did you receive an information pamphlet explaining the hearing screening programme and the importance thereof and stating the audiology practice contact details?

\begin{tabular}{|l|l|l|}
\hline Yes & & V28 \\
\hline No & & V29 \\
\hline Unsure & & V30 \\
\hline
\end{tabular}

16. Are you aware of the negative impact hearing loss can have on a child's development?

\begin{tabular}{|l|l|l|}
\hline Yes & & V31 \\
\hline No & & V32 \\
\hline Unsure & & V33 \\
\hline
\end{tabular}

\section{SECTION C: INITIAL TEST AND FOLLOW-UP RETEST}

17. Your child's hearing was screened with your informed consent. Are you aware of the results of the hearing screening?

\begin{tabular}{|l|l|l|}
\hline Yes & & V34 \\
\hline No & & V35 \\
\hline Unsure & & V36 \\
\hline
\end{tabular}

18. It was recommended that you bring your child for a follow-up hearing screening. Are you aware of this?

\begin{tabular}{|l|l|l|}
\hline Yes & & V37 \\
\hline No & & V38 \\
\hline Unsure & & V39 \\
\hline
\end{tabular}

19. If yes, how were you made aware of the recommended follow-up hearing screening? You may select more than one answer.

\begin{tabular}{|l|l|l|}
\hline $\begin{array}{l}\text { There was a sticker on the } \\
\text { clinic card recommending } \\
\text { follow-up }\end{array}$ & V40 \\
\hline The audiologist informed me & & V41 \\
\hline $\begin{array}{l}\text { The paediatrician informed } \\
\text { me }\end{array}$ & V42 \\
\hline Other & V43 \\
\hline
\end{tabular}


20. If you are aware of the recommended follow-up retest what is the reason you did not bring your child?

\begin{tabular}{|l|l|l|}
\hline $\begin{array}{l}\text { I was not made aware that } \\
\text { the follow-up test cost is } \\
\text { included in the initial test cost }\end{array}$ & V44 \\
\hline $\begin{array}{l}\text { My medical aid did not pay } \\
\text { for the initial test }\end{array}$ & V45 \\
\hline $\begin{array}{l}\text { I was not reminded to bring } \\
\text { my child to repeat the test }\end{array}$ & $V 46$ \\
\hline I feel it is not necessary & V47 \\
\hline $\begin{array}{l}\text { I was unaware of the practice } \\
\text { contact details }\end{array}$ & $V 48$ \\
\hline $\begin{array}{l}\text { The paediatrician did not } \\
\text { recommended the retest }\end{array}$ & V49 \\
\hline Other & V50 \\
\hline
\end{tabular}

\section{SECTION D: ONE YEAR FOLLOW-UP}

21. Would you be interested in bringing your child for a follow-up retest?

\begin{tabular}{|l|l|l|}
\hline Yes & & V54 \\
\hline No & & V55 \\
\hline Unsure & & V56 \\
\hline
\end{tabular}

22. If not, why not? You may select more than one answer.

\begin{tabular}{|l|l|l|}
\hline $\begin{array}{l}\text { The medical aid does not } \\
\text { pay, I am unwilling to pay } \\
\text { myself }\end{array}$ & V57 \\
\hline I feel it is not necessary & & V58 \\
\hline $\begin{array}{l}\text { The paediatrician did not } \\
\text { recommended the retest }\end{array}$ & V59 \\
\hline Other & V60 \\
\hline
\end{tabular}

23. Is there any comment you would like to make?

Your participation is much appreciated, thank you! 